\title{
Evaluation of Yashtimadhu (Glycyrrhiza glabra) Active Phytochemicals against Novel Coronavirus (SARS-CoV-2)
}

\section{Maurya DK ${ }^{1,2 *}$}

${ }^{1}$ Radiation Biology \& Health Sciences Division, Bhabha Atomic Research Centre, Mumbai 400 085, India ${ }^{2}$ Homi Bhabha National Institute, Anushaktinagar, Mumbai-400094, India

*Corresponding author: Dharmendra Kumar Maurya, Scientific Officer/F, Free Radical Biology Section, Radiation Biology \& Health Sciences Division, Bhabha Atomic Research Centre, Mumbai 400 085, Maharashtra, India

Received: J uly 28, 2021; Accepted: September 22, 2021; Published: September 29, 2021

\begin{abstract}
Corona Virus Disease 2019 (COVID-19) caused by a novel coronavirus has spread all over the globe and become pandemic now. Until now several vaccines have come-up with limited efficacy for the managing COVID-19. However, several studies are still going on to find suitable therapeutic drugs which can target viral proteins or host receptor. Hence the search for plant-based anti-viral agents against the SARS-CoV- 2 is promising because several plants have been shown to possess anti-viral activities against different viruses. Here, we used in silico approach to explore the use of Indian Ayurvedic herbs, Yashtimadhu against COVID-19. In the present study we have evaluated the effectiveness of phytochemicals found in Yashtimadhu against Main Protease (Mpro), Spike (S) protein and RNA-dependent RNA polymerase (RdRp) of SARS-CoV-2 as well as human angiotensin converting enzyme 2 (ACE2) receptor and furin protease. Apart from this, we have also predicted the anti-viral, in-silico druglikeness, pharmacokinetics, toxicity, protein targets, and their function for the phytochemicals found in the Yashtimadhu. Our study shows that several phytochemicals found in this plant have potential to bind with important proteins of SARS-CoV-2 which are essential for viral infection and replication. Overall our study provides scientific basis in terms of binding of active ingredients present in Yashtimadhu with SARS-CoV-2 target proteins. Molecular docking and MD simulation studies reveal that Yashtimadhu may inhibit the viral severity by interfering with viral entry as well as its multiplication in the infected persons. Thus, Yashtimadhu may be helpful in the prevention and management of the COVID-19.
\end{abstract}

Keywords: COVID-19; SARS-CoV-2; Phytochemicals; Ayurvedic herbs; Molecular docking; MD simulation

\section{Introduction}

SARS-CoV-2 is the seventh coronavirus (CoV) known to infect humans; SARS-CoV, MERS-CoV and SARS-CoV-2 has caused three recent major global epidemics, whereas HKU1, NL63, OC43 and $229 \mathrm{E}$ are associated with mild symptoms [1,2]. As compared to SARS-CoV and MERS-CoV, SARS-CoV-2 virus exhibits faster human-to-human transmission and high infectivity rate. Hence, World Health Organization (WHO) has declared it as a global emergency. Researchers from all-over the world are trying to find possible cure for this infectious disease, COVID-19. Phylogenetic analysis show that SARS-CoV-2 has very high nucleotide sequence identity with SARS-CoV (79.7\%) [3]. The envelope and nucleocapsid proteins of SARS-CoV-2 are two evolutionarily conserved regions, with sequence identities of $96 \%$ and $89.6 \%$, respectively. Like other CoVs, SARS-CoV-2 has a positive-sense single-stranded RNA as genome and four structural proteins, namely the S (spike), E (envelope), $\mathrm{M}$ (membrane), and $\mathrm{N}$ (nucleocapsid) proteins in which, $\mathrm{N}$ protein holds the RNA genome, and the $\mathrm{S}$, E, and $\mathrm{M}$ proteins together create the viral envelope. CoVs infect host cells using their spike proteins on the surface by making interaction with cognate receptors present on the host cell surface. The spike proteins of SARS-CoV-2 has high affinity to the cellular receptor angiotensinconverting enzyme 2 (ACE2) for their entry inside the cells [4]. The higher binding affinity of SARS-CoV-2 spike protein to the human receptor ACE2 is due to presence of functional polybasic furin cleavage site at the S1-S2 boundary in the spike glycoprotein [5]. Zoonosis is common among CoVs and they can be transmitted from one animal species to another, animals to humans, and humans to humans [6,7]. In search of an effective therapeutics against SARSCoV-2, researchers are screening existing broad-spectrum anti-virals, small molecule libraries, FDA approved drug libraries and rational drug design approach $[3,8]$. Until now several vaccines have come-up with limited efficacy in managing COVID-19 disease and several are at advance stage of their release [9-11]. Apart from this, many new chemical entities and re-purposed drugs are also being tested against SARS-CoV-2 [12,13]. Some of the currently used drugs for managing COVID-19 disease are Remdesivir, Favipiravir, Galidesivir, Actemra, Azithromycin, Thalidomide, Hydroxychloroquine/Chloroquine, and Ivermectin in combination with doxycycline which have shown limited efficacy [14]. Apart from these, exploring medicinal plants for the management of COVID-19 both as prophylaxis and therapeutic purpose will be an alternate approach. Numerous herbs, spices and their active phytochemicals have shown significant activity in in silico study against COVID-19.

Ayurvedic medicines are used in Indian subcontinent since the Vedic period and they have long history for treatment of viral diseases 
[15-17]. Yashtimadhu (Glycyrrhiza glabra), is one of the most potent rasayana drugs in Ayurveda (also known as Licorice and Mulethi) used alone or in combination with other herbs in preparation of several Ayurvedic medicines and food supplements worldwide for centuries. Commercially, Yashtimadhu is added to chewing gum, chocolate candy, cigarettes, smoking mixtures, chewing tobacco and snuff as sweetening agents [18]. It possesses several beneficial effects including treatment of various respiratory disorders such as cough, cold and flu [18]. In Ayurveda, Yashtimadhu is being used either alone or in combination with different other herbs. This can be consumed as powder or tablets or as a component of Ayurvedic Kadha (decoction). Traditionally Yashtimadhu was consumed by chewing or its powder mixed with honey or ghee. Yashtimadhu and its active ingredients have significant anti-inflammatory property [19-22]. Clinically, Yashtimadhu has been used for prevention and treatment of oral mucositis after radio- and chemo-therapy in cancer patients [23]. The most important bioactive compounds of Yashtimadhu, Glycyrrhizin was shown to inhibit SARS-CoV replication as well as inhibits adsorption and penetration of the virus at early stage of the replicative cycle $[24,25]$.

In the present study, the phytochemicals of Yashtimadhu were docked with different viral proteins (such as spike, main protease, RNA dependent RNA polymerase) and also with host cell receptors \& protease (such as human ACE2 and furin). Since SARS-CoV-2 have high rate of infectivity and transmission due to its spike protein, so we have also performed the MD simulation using spike as well as RdRp with two important phytochemicals of Yashtimadhu namely, Glycyrrhizin and Glycyrrhetic acid. Our study predicted that many of the phytochemicals found in Yashtimadhu possess significant affinity towards functional region of viral proteins including spike, proteases, and polymerase as well as host surface receptor and protease. Other than this, we have also predicted the anti-viral, in-silico drug-likeness, pharmacokinetics, and toxicity of the selected phytochemicals found in the Yashtimadhu. Finally different phytochemicals were used to predict their targets which was used to explore it function using network biology. Our study provides a scientific justification for the usages of Yashtimadhu for the prevention of viral infection, pathogenicity and reducing disease-severity in COVID-19 patients. Thus Yashtimadhu can be combined with the conventional treatment plan for management of COVID-19.

\section{Materials and Methods}

\section{List of the phytochemicals found in Yashtimadhu}

Yashtimadhu have an array of the phytochemicals. Some of well-known phytochemicals include, Abscisic, Apioside, Glabridin, Glabrin A, Glabrin B, Glycyrrhetic acid (also known as glycyrrhetinic Acid), Glycyrrhizin (also known as Glycyrrhizic Acid/Glycyrrhizinic Acid), Hispaglabridin, Isoliquiritigenin, Isoliquiritin, Licochalcone A, Liquiritigenin, Liquiritin, Liquiritin Apioside, Prenyllicoflavone A, Salicyclic Acid, Shinflavanone, Shinpterocarpin, Sitosterol, Stigmasterol, Syringic acid, Trans-Ferulic acid [18,26,27]. 3D structures of these different phytochemicals were downloaded from PubChem (https://pubchem.ncbi.nlm.nih.gov) in Structure-Data File (SDF).

\section{Protein structures}

In order to study the mode of interaction of different phytochemicals with various SARS-CoV-2 proteins and receptors found on virus and host cells, molecular docking was performed. We have used following PDB ID's 6lu7 (SARS-CoV-2 main protease), 6m0j (SARS-CoV-2 spike), 6m71 (SARS-CoV-2 RdRp), 6m0j (ACE2) and $5 \mathrm{mim}$ (proprotein convertase, furin). All the protein structures were retrieved from protein data bank (www.rcsb.org) and cleaned using USCF Chimera software [28].

\section{Molecular docking}

PyRx virtual screening tool was used for preparation of the input files and performing molecular docking using Vina wizard [29,30]. For preparation of protein input files, all water molecules, ligands and ions were removed from ${ }^{*}$.pdb files. The polar hydrogens were added to protein structure and prepared files were saved in ${ }^{*}$.pdbqt format. The molecule's energy was minimized using energy minimization tools of PyRx virtual screening software and ligands were saved in ${ }^{*}$.pdbqt format after adding polar hydrogens for further docking process. 2D interaction of the ligand and protein was visualized using Discovery Studio Visualizer. Region-specific docking was performed against SARS-CoV-2 main protease and spike protein as well as for human ACE2 \& Furin protease. Following AutoDock Vina docking parameters such as (center_x $=-16.69$, center_y $=27.23$, center_z $=68.46$, size $\_x=36.65$, size $\_y=42.12$, size $\left.\_z=50.40\right)$, (center_x $=$ -32.483 , center_y $=26.077$, center_z $=7.923$, size_x $=52.974$, size_y $=46.699$, size $\left.\_z=30.699\right),\left(\right.$ center $\_x=-25.0997$, center $\_y=19.903$, center_z $=3.047$, size_x $=78.872$, size_y $=67.603$, size_z $=35.866$ ) and (center_x $=32.41$, center_y $=-37.97$, center_z $=-11.64$, size_x $=71.93$, size $\_y=55.05$, size $\left.\_z=47.46\right)$ were used for SARS-CoV-2 main protease (PDB ID: 6LU7), SARS-CoV-2 spike (PDB ID: 6m0j), human ACE2 (PDB ID: 6m0j) and furin (PDB ID: 5MIM) respectively. For docking RdRp (PDB ID: 6m71) NSP7 and NSP8 was removed from the NSP12 and grid box for docking parameter was set at the NSP12-NSP7 and NSP12-NSP8 interface. Docking parameters used for NSP12 were center_x $=112.289$, center_y $=131.245$, center_z $=$ 141.597, size_x $=83.597$, size_y $=69.959$, size_ $z=45.240$.

\section{Molecular dynamics simulation}

Out of several important proteins, Spike and RdRp play important role in the SARS-CoV-2 infection and multiplication respectively. Thus both these proteins are considered as important druggable targets against SARS-CoV-2. In Yashtimadhu root, Glycyrrhizin and Glycyrrhetic acid are found in the large quantity so they are selected for MD simulation with SARS-CoV-2 Spike and RdRp. All the MD simulations were performed using GROMACS version 2019.4 software with Gromos53a6.ff Force-field [31]. The topology files for protein was prepared using pdb2gmx module of GROMACS and of ligands was prepared using Prodrg server (http://prodrg1.dyndns. org/) [32]. In brief, proteins were solvated using simple point charge (SPC) water model and counter ions $\left(\mathrm{Na}^{+}\right.$and $\left.\mathrm{Cl}^{-}\right)$were added to neutralize the system. The system was equilibrated with temperature $310 \mathrm{~K}$ and pressure 1 bar by two consecutive 100 ps simulation with a constant number of particles, volume, and temperature (NVT) with a constant number of particles, pressure, and temperature (NPT). After equilibration, a production simulation was performed for 500 nanoseconds. All the simulation runs were carried out in triplicates.

\section{Trajectory analysis}

After completion of MD simulation, trajectory analysis was 
performed using in-built GROMACS analysis tools. For studying the stability and flexibility for protein-ligand complexes, root mean square deviation (RMSD) based on whole protein and Root Mean Square Fluctuation (RMSF) based on the C-alpha were analysed using gmx rms, and gmx rmsf tools, respectively. For studying the global motion of a protein during the simulation, Principal Component Analysis (PCA) was carried out. PCA was achieved by diagonalizing and solving the eigenvalues and eigenvectors for the covariance matrix using GROMACS analysis tool gmx cover. Further, another GROMACS analysis tool, gmx anaeig was employed to calculate the overlap between principal components and coordinates of the trajectory.

\section{MM-PBSA binding free energy calculation}

After completion of MD production run, Mechanic/PoissonBoltzmann Surface Area (MM-PBSA) calculations were performed to predict the binding energies. The binding free energy comprises of potential energy, polar and non-polar solvation energies and delivers an indication of the biomolecular interactions between protein and ligand. A lower and negative binding free energy indicate a stronger ligand binding. Here in this study, MM-PBSA binding free energies were calculated using a GROMACS script 'g_mmpbsa' [33]. Binding energies were extracted using MmPbSaStat.py script. The binding energy was calculated using the following equation:

$$
\Delta \mathrm{G}_{\text {binding }}=\mathrm{G}_{\text {complex }}-\left(\mathrm{G}_{\text {receptor }}-\mathrm{G}_{\text {ligand }}\right)
$$

Where, $\Delta G_{\text {binding }}$ represents the total binding energy of the complex, binding energy of free receptor is $G_{\text {receptor }}$ and that of unbounded ligand is represented by $\mathrm{G}_{\text {ligand }}$.

\section{Prediction of antiviral property of the phytochemicals}

Antiviral property of the different phytochemicals was predicted using "AVCpred" an open source predicton server (http://crdd.osdd. net/servers/avcpred/batch.php) [34]. This predict antiviral effect of the search molecules for general (26 viruses) as well as specific viruses such as Human Immunodeficiency Virus (HIV), Hepatitis C Virus (HCV), Hepatitis B Virus (HBV) and Human Herpes Virus (HHV).

\section{In-silico drug-likeness and pharmacokinetic property prediction}

After performing molecular docking and MD simulation, insilico drug-likeness and important pharmacokinetic properties of the selected phytochemicals which bind will SARS-CoV-2 spike, Mpro, RdRp and human ACE2 \& Furin proteins were predicted using pkCSM online prediction platforms [35]. This online server calculates pharmaceutically applicable properties such as molecular weight, octanol-water partition coefficient $(\log \mathrm{P})$, number of $\mathrm{H}$-bond donor, number of $\mathrm{H}$-bond acceptor and number of rotatable bonds. In addition it also calculates ligands Absorption, Distribution, Metabolism, Excretion and Toxicity (ADMET) parameters like water solubility, human intestinal absorption, total clearance, AMES test, human maximum tolerated dose, hepatotoxicity and many more parameters.

\section{Network biology}

For studying the network biology first we predicted the phytochemicals targets, after that prepared the protein-protein interact (PPI) diagram and predicted the Gene Ontology (GO) processes and various KEGG pathways influenced. Briefly, targets

Table 1: Docking score against SARS-CoV-2 spike, main protease \& RdRp and human ACE2 \& Furin.

\begin{tabular}{|c|c|c|c|c|c|}
\hline \multirow{2}{*}{ Compounds } & \multicolumn{5}{|c|}{ Target molecules; binding energy $(\mathrm{kcal} / \mathrm{mol})$ (Only those phytochemicals are included in the table which have binding energy $\leq-7.0$ ) } \\
\hline & $\begin{array}{c}\text { SARS-CoV-2 spike protein } \\
\text { (PDB ID: } 6 \mathrm{m0j} \text { ) }\end{array}$ & $\begin{array}{l}\text { SARS-CoV-2 main protease } \\
\text { (PDB ID: 6lu7) }\end{array}$ & $\begin{array}{l}\text { SARS-CoV-2 RdRp (PDB } \\
\text { ID: } 6 \mathrm{~m} 71 \text { ) }\end{array}$ & $\begin{array}{l}\text { Human ACE2 (PDB } \\
\text { ID: } 6 \mathrm{m0j})\end{array}$ & $\begin{array}{l}\text { Human Furin (PDB ID: } \\
5 \mathrm{mim})\end{array}$ \\
\hline \multicolumn{6}{|l|}{ Phytochemicals } \\
\hline Apioside & -7 & -7.9 & -7.8 & -7.8 & -8.5 \\
\hline Glabrin B & -7.3 & -8.9 & -8 & -7.3 & -8.4 \\
\hline Glycyrrhetic acid & -8.3 & -8.2 & -8.4 & -7 & -7.8 \\
\hline Glycyrrhizin & -7.3 & -7.3 & -8.4 & -7.3 & -8.5 \\
\hline Hispaglabridin A & -7.3 & -8 & -8.3 & -7 & -7.7 \\
\hline Liquiritin & -7.1 & -7.4 & -7.9 & -7.2 & -8.3 \\
\hline Shinflavanone & -7.8 & -8.4 & -8.5 & -7.4 & -8.5 \\
\hline Shinpterocarpin & -7.2 & -8.1 & -7.8 & -8.2 & -8.6 \\
\hline Liquiritin apioside & & -7.9 & -8.8 & -7.5 & -7.9 \\
\hline Isoliquiritigenin & & -7.5 & -7.7 & -7 & -7 \\
\hline Glabrin A & & -7.3 & -7.9 & & -8.2 \\
\hline Liquiritigenin & & -7.7 & -7.2 & -7.3 & \\
\hline Isoliquiritin & & -7.5 & & & -7.9 \\
\hline Licochalcone A & & -7.9 & & & -7.4 \\
\hline Stigmasterol & & & -7.9 & & -7.9 \\
\hline Beta-sitosterol & & & & & -7.2 \\
\hline
\end{tabular}


of phytochemicals were predicted using DIGEP-Pred [36] at the pharmacological activity $(\mathrm{Pa})>0.5$ and the up-regulated and downregulated proteins were enriched using STRING for Homo sapiens [37]. Further, a PPI network between upregulated and downregulated targets were constructed using Cytoscape after removing any duplicates targets. From the PPI various GO processes and KEGG pathways influenced by upregulated and downregulated targets proteins were identified.

\section{Results}

\section{Molecular docking}

Our molecular docking study revealed that different phytochemicals found in Yashtimadhu have significant binding affinity with various SARS-CoV-2 proteins i.e. main protease, spike \& RdRp and host macromolecular targets such as human ACE2 and furin proteins (Table 1). SARS-CoV-2 spike protein interacts with the host ACE2 receptor present on the surface of the host cells for their entry. Furin (a kind of proprotein convertase) is another protease found in the host cells which acts on the viral spike protein and facilitates the interaction of spike with the human ACE2. Figure 1, shows the predicted binding of important phytochemicals found in Yashtimadhu against SARS-CoV-2 spike protein and their different protein residues which are involved in the interaction. Some of the important phytochemicals having high binding affinity with Spike are Glycyrrhetic acid, Shinflavanone, Glycyrrhizin \& Glabridin and their predicted binding energies are -8.3, -7.8, 7.3 and $-7.2 \mathrm{kcal} / \mathrm{mol}$ respectively. All these molecules have different type of interaction with different residues of the spike protein. It was observed that all of these molecules contribute at least 2 conventional hydrogen bonds with target protein. Other than this Glycyrrhetic acid and Glabridin interacted using 6 alkyl or pi-alkyl bond (Figure 1).

Figure 2, shows the predicted binding of some key phytochemicals of Yashtimadhu against human ACE2 receptor and their different protein residues which are involved in the interaction. These phytochemicals are Shinpterocarpin, Apioside, Glabridin, Glycyrrhetic acid, Liquiritin apioside and Shinflavanone. Their predicted binding energies are -8.2, -7.8, -7.7, -7.6, -7.5 and -7.4 kcal/ mol respectively. As for types and number of bonding is concern Apioside, Liquiritin apioside, and Glycyrrhetic acid have 7, 5 and 3 conventional hydrogen bonding respectively whereas Glabridin, Shinpterocarpin, and Glycyrrhetic acid makes 6, 5 and 4 alkyl or pialkyl bond respectively (Figure 2).

Figure 3, shows the predicted binding of some important phytochemicals of Yashtimadhu against human furin protease and different protein residues which are involved in the interaction. These phytochemicals are Shinpterocarpin, Apioside, Glycyrrhizin, Shinflavanone, Glabrin B, Glycyrrhetic acid, Liquiritin, Glabridin, Glabrin A and Prenyllicoflavone A. Their predicted binding energies are $-8.6,-8.5,-8.5,-8.5,-8.4,-8.3,-8.3,-8.2,-8.2$ and $-8.1 \mathrm{kcal} / \mathrm{mol}$ respectively.

The SARS-CoV-2 main protease (Mpro), plays a pivotal role in viral gene expression and replication. Crucial maturation cleavage events within the viral precursor polyprotein are mediated by the Mpro. Figure $4 \mathrm{a}$ and $4 \mathrm{~b}$, shows the predicted binding of important phytochemicals of Yashtimadhu against Mpro and different protein residues which are involved in the interaction. These phytochemicals are Glabrin B, Shinflavanone, Glycyrrhetic acid, Shinpterocarpin, Glabridin, Hispaglabridin A, Liquiritin apioside, Licochalcone A, Apioside, Prenyllicoflavone A, Liquiritigenin, Isoliquiritin and

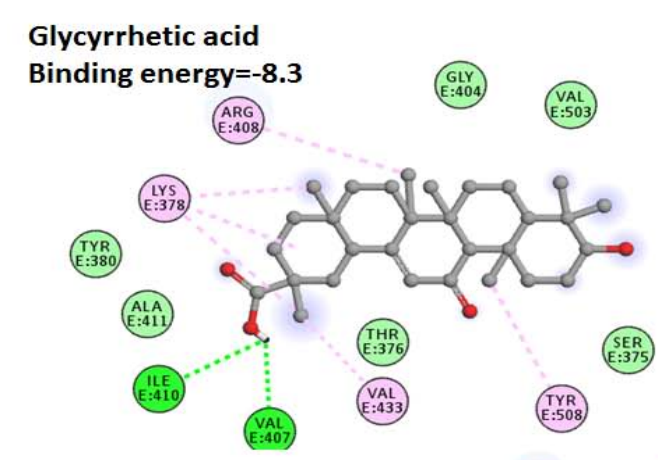

Glycyrrhizin

(ASP

Binding energy=-7.3

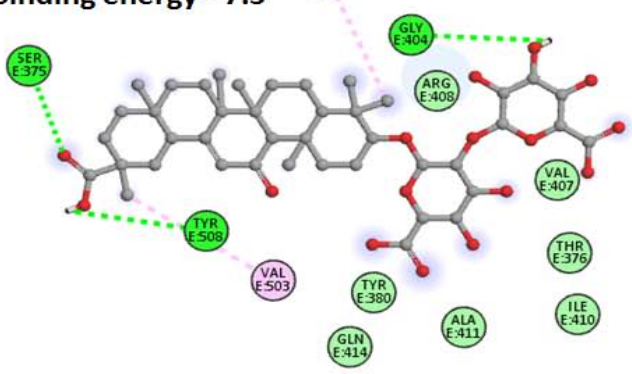

Shinflavanone Binding energy=-7.8

(61Y) ASN

PPAE)
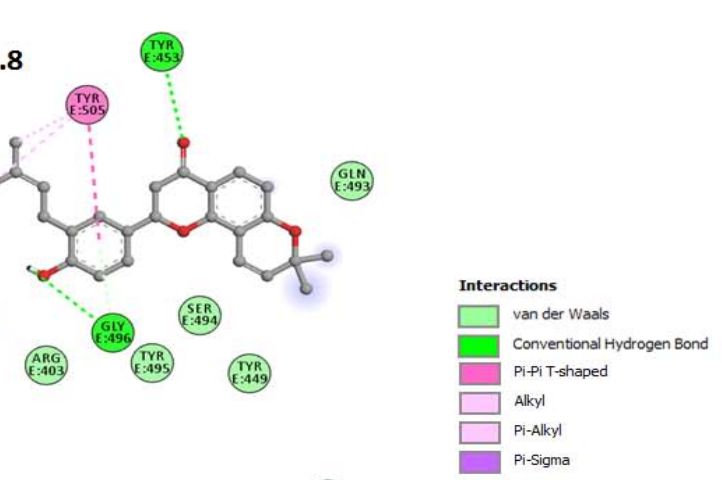

Glabridin Binding energy=-7.2

(A:A)
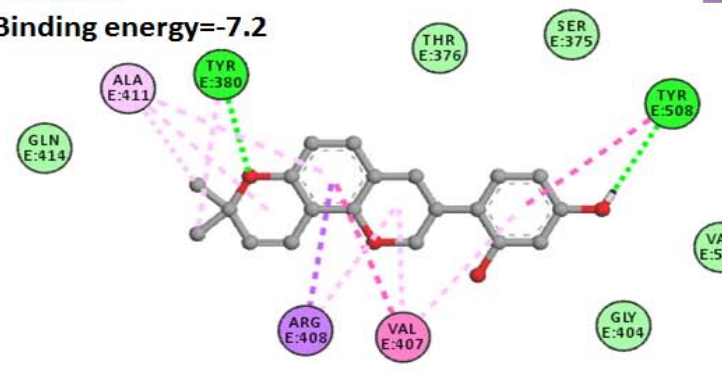

(A4A)

Figure 1: The predicted binding and 2D interaction of selected phytochemicals from Yashtimadhu against SARS-CoV-2 Spike CTD (PDB ID: 6M0J) and their different protein residues which are involved in the interaction. 

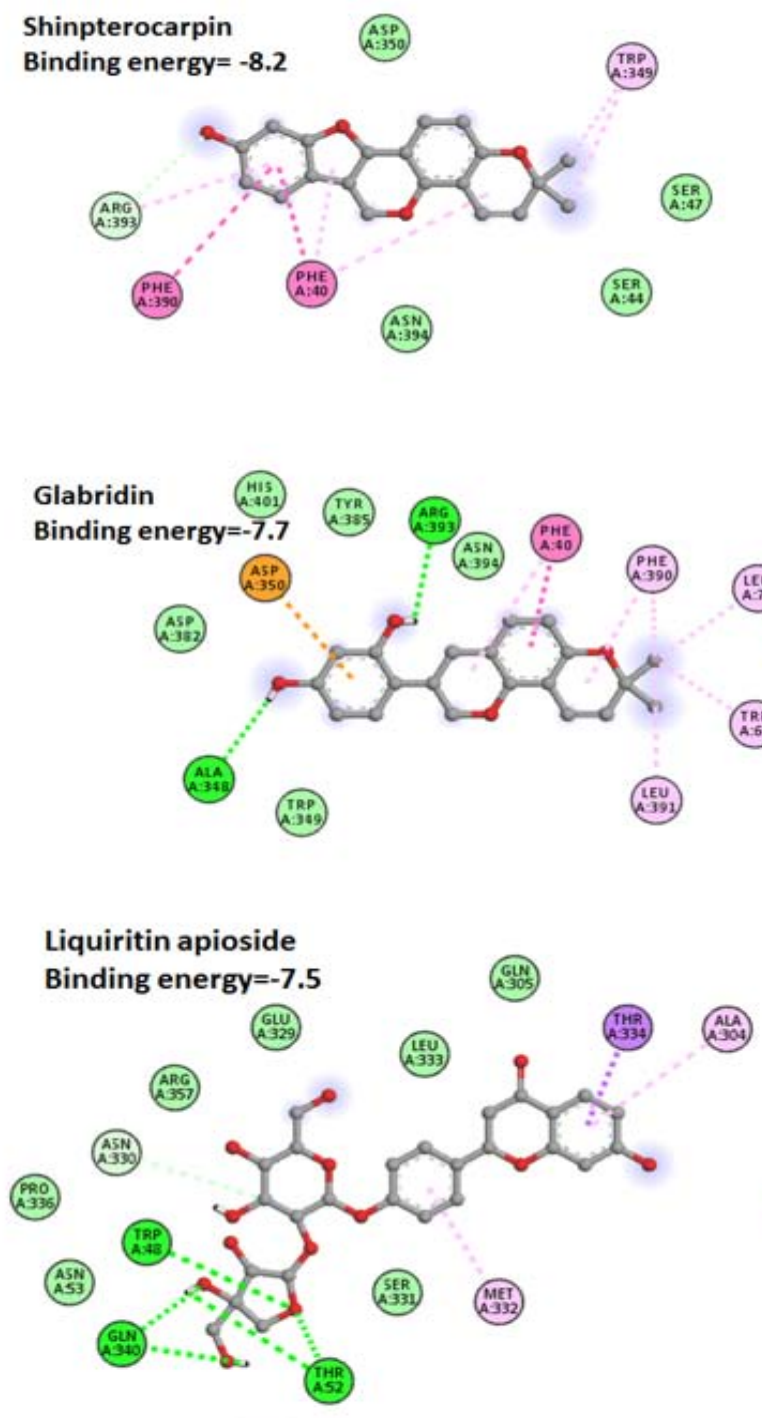

(i:장

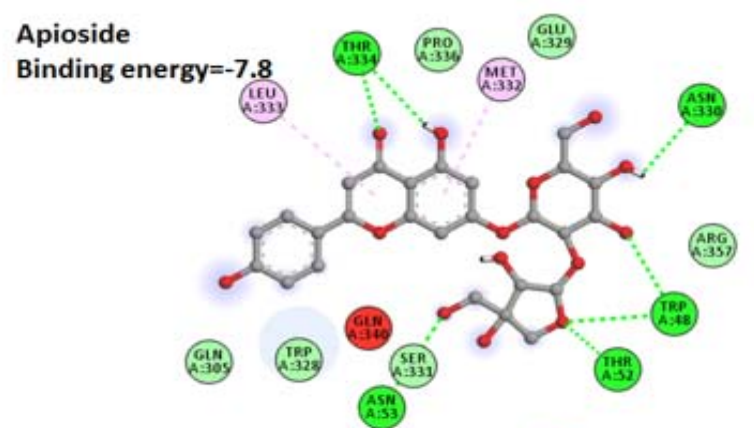

Glycyrrhetic acid

(Ai:日) Binding energy $=-7.6$

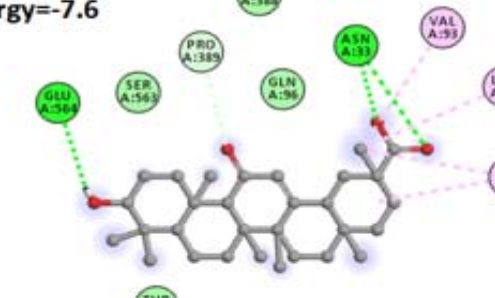

(i:i)

i:20

\section{Shinflavanone \\ Binding energy $=-7.4$}

(iin:

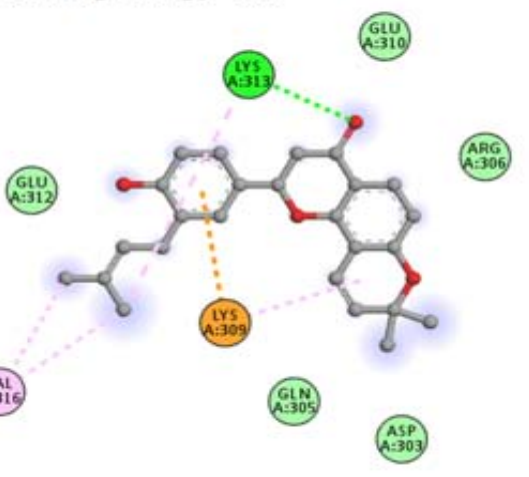

Figure 2: The predicted binding and 2D interaction of selected phytochemicals from Yashtimadhu against human ACE2 receptor (PDB ID: 6M0J) and their different protein residues which are involved in the interaction.

Isoliquiritigenin. Their predicted binding energies are $-8.9,-8.4$, $-8.2,-8.1,-8.1,-8.0,-7.9,-7.9,-7.9,-7.7,-7.7,-7.5$ and $-7.5 \mathrm{kcal} / \mathrm{mol}$ respectively.

The RNA-dependent RNA polymerase (RdRp, also named NSP12) is the central component of SARS-CoV-2 replication/ transcription machinery. Figure 5, shows the predicted binding of important phytochemicals of Yashtimadhu against RdRp and their different protein residues which are involved in the interaction. These phytochemicals are Liquiritin apioside, Shinflavanone, Glycyrrhizin, Glycyrrhetic acid, Hispaglabridin A and Prenyllicoflavone A. Their predicted binding energies are $-8.8,-8.5,-8.4,-8.4,-8.3$ and $-8.3 \mathrm{kcal} /$ mol respectively. As for types and number of bonding is concern, Liquiritin apioside has 5 and Glycyrrhizin has 8 convention hydrogen bonding with RdRp whereas Hispaglabridin A and Prenyllicoflavone A makes 8 and 10 alkyl or pi-alkyl bonds (Figure 5).

\section{MD simulation}

Molecular docking study provides static poses of the most favoured conformations of a molecule in the binding pocket of a protein. MD simulation is helpful in studying the immovability and steadiness of binding pose gained from docking. Working principle of the $\mathrm{MD}$ simulation is based on the classical Newtonian physics. It give information about the actual movement and structural perturbations of a protein in its biological environment. Thus, MD simulation was conducted to examine the stability and dynamics of protein to confirm the docking results and get more insight into the steadiness of ligand-protein complex. For this MD simulations was carried out using SARS-CoV-2 spike and RdRp complex with Glycyrrhizin or Glycyrrhetic acid in the solvated states for $500 \mathrm{~ns}$.

The results of MD simulations have been examined on the basis of root mean square deviation (RMSD) and root mean square 


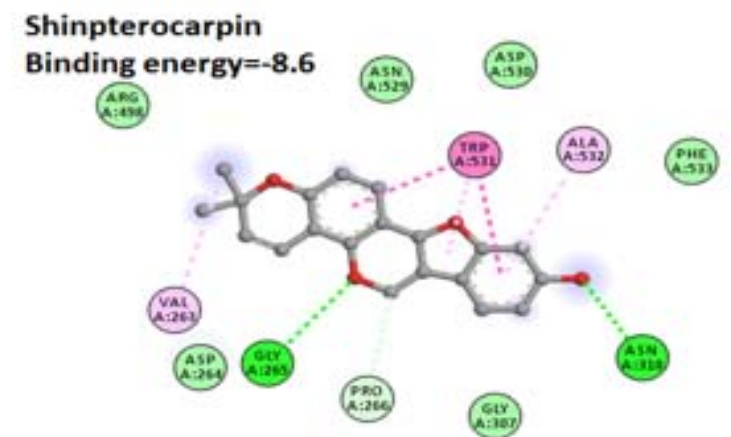

Glycyrrhizin Binding energy $=-8.5$

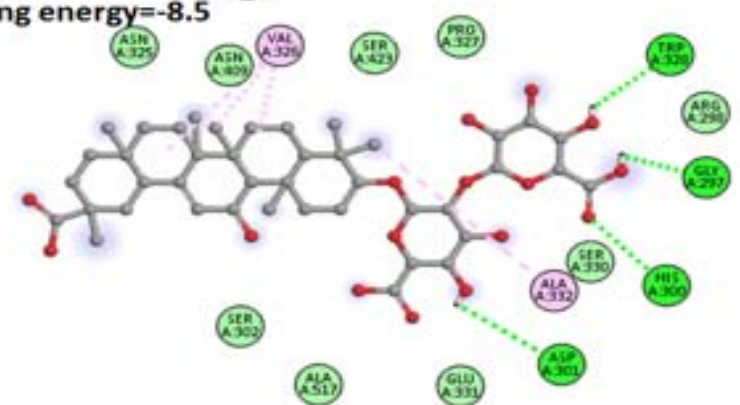

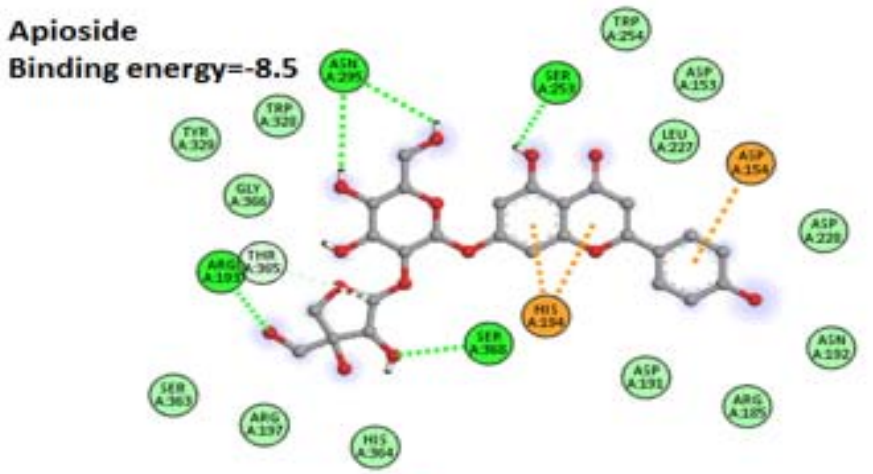

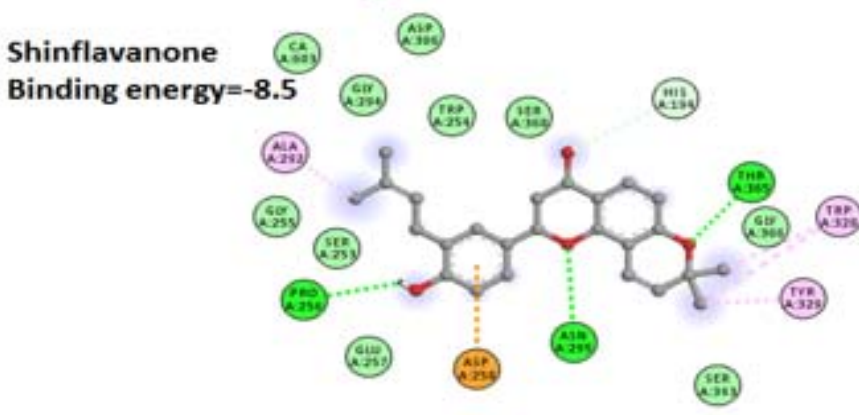

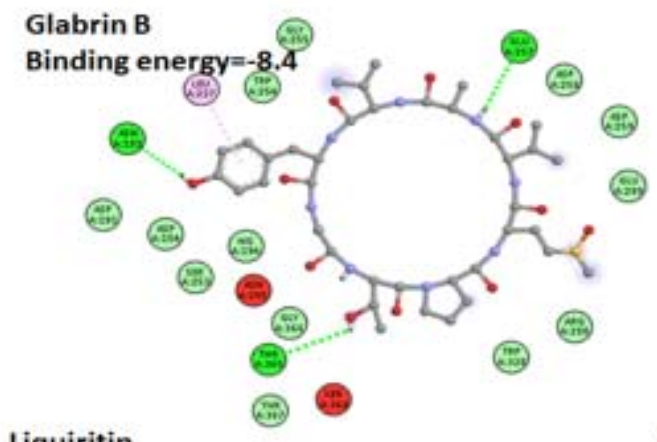

Liquiritin

Binding energy $=-8.3$

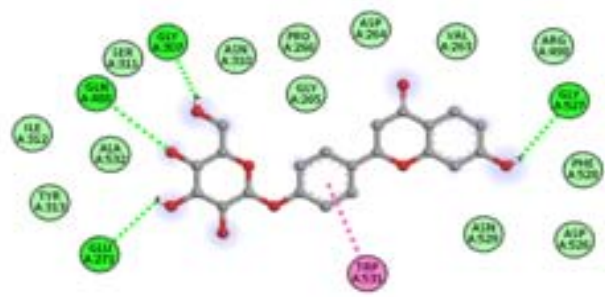

\section{Glycyrrhetic acid Binding energy $=-8.3$}
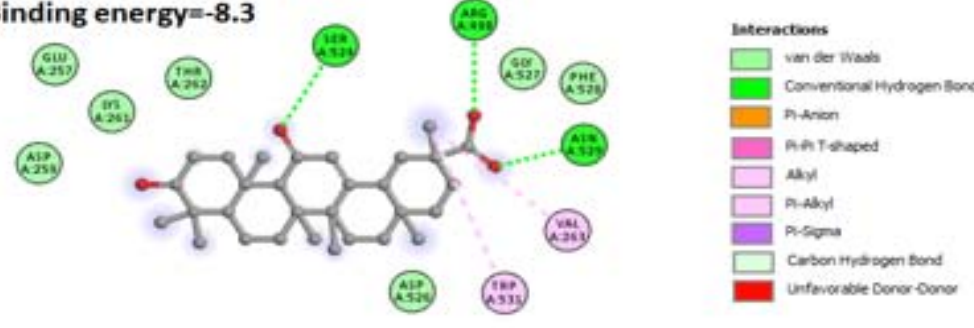

Glabridin

Binding energy $=-8.2$

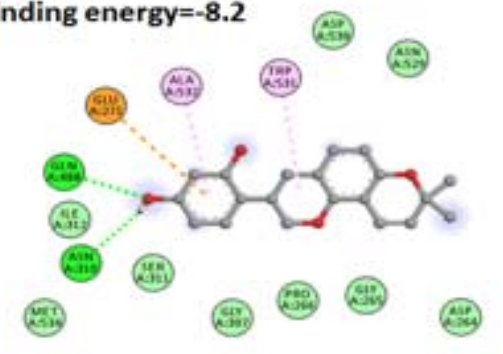

Prenyllicoflavone $\mathrm{A}$
Binding energy=-8.1

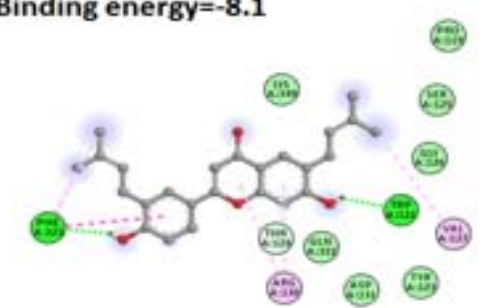

Figure 3: The predicted binding and 2D interaction of selected phytochemicals from Yashtimadhu against human furin protease (PDB ID: 5MIM) and their different protein residues which are involved in the interaction.

fluctuation (RMSF). RMSD is a well-known estimator of equilibration and protein stability. Based on the obtained MD trajectories, RMSD values of the protein backbone in complexes with the Glycyrrhizin or Glycyrrhetic acid were computed.

The RMSD plot analysis indicates that for both Spike and RdRp, the RMSD values showed an initial steady increase and then reached equilibrium during the rest simulation period (Figure 6). However, any variations noticed were in order of $\sim 0.15 \mathrm{~nm}$ showing that the complex has not undergone large conformational changes. To explore the local protein flexibility and plasticity, the time average of RMSF values of spike and RdRp in presence of Glycyrrhizin or Glycyrrhetic acid over simulation period were calculated. RMSF with respect to amino acid for all the studied proteins were plotted and we did not find any major fluctuation except for a few places where moderate 

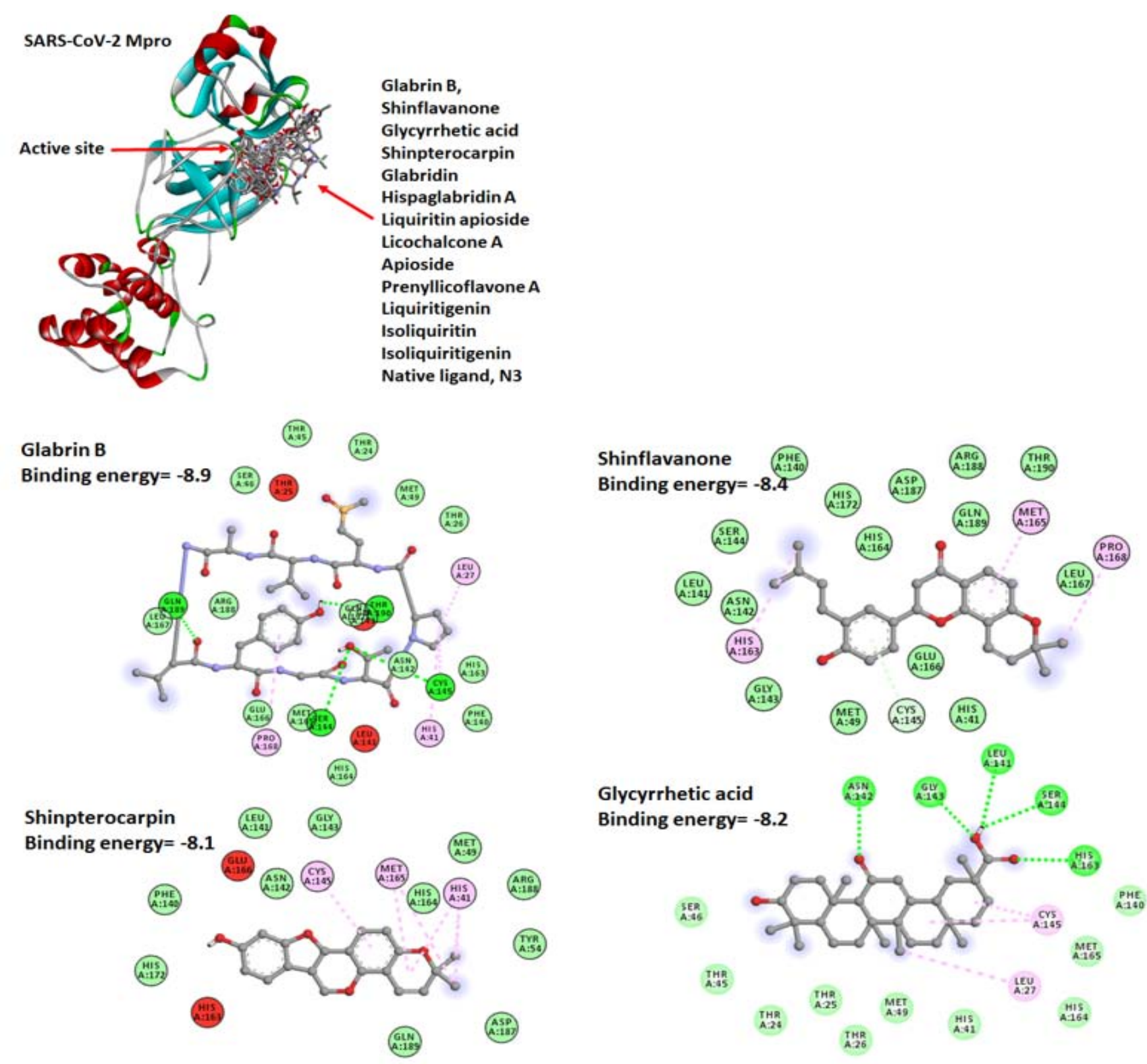

Figure 4a: The predicted binding and 2D interaction of selected phytochemicals from Yashtimadhu against SARS-CoV-2 Mpro (PDB ID: 6LU7) and their different protein residues which are involved in the interaction.

fluctuation were observed (Figure 7). RMSF with respect to amino acid for all the studied proteins were plotted and we did not find any major fluctuation except for a few places where moderate fluctuation were observed.

\section{Principal component analysis}

PCA of MD trajectories of SARS-CoV-2 spike and RdRp in complexed with Glycyrrhizin or Glycyrrhetic acid was conducted to study the collective motion of the respective unbound and ligandbound protein on the trajectories. The overlap between PC and coordinates of the trajectory are shown in Figure 8. During PCA, lower eigenvalues signify lower expansion of protein indicating more compactness throughout the simulation. Figure 8 shows that ligands bound proteins covered a smaller region of phase space compared with the unbound proteins for all the studied complexes.

\section{MM/PBSA calculation}

After performing simulation, MD output file were further used to calculate average free binding energy using g_mmpbsa package and $\mathrm{MmPbSaStat}$.py python script (Table 2). The final binding energy is a cumulative sum of van der Wall, electrostatic, polar solvation, and SASA energy.

As shown in Table 2, except for the polar solvation energy, all other forms of energy contributed positively to the interaction between spike with Glycyrrhizin or Glycyrrhetic acid. For RdRp, except for the polar solvation energy, all other forms of energy 


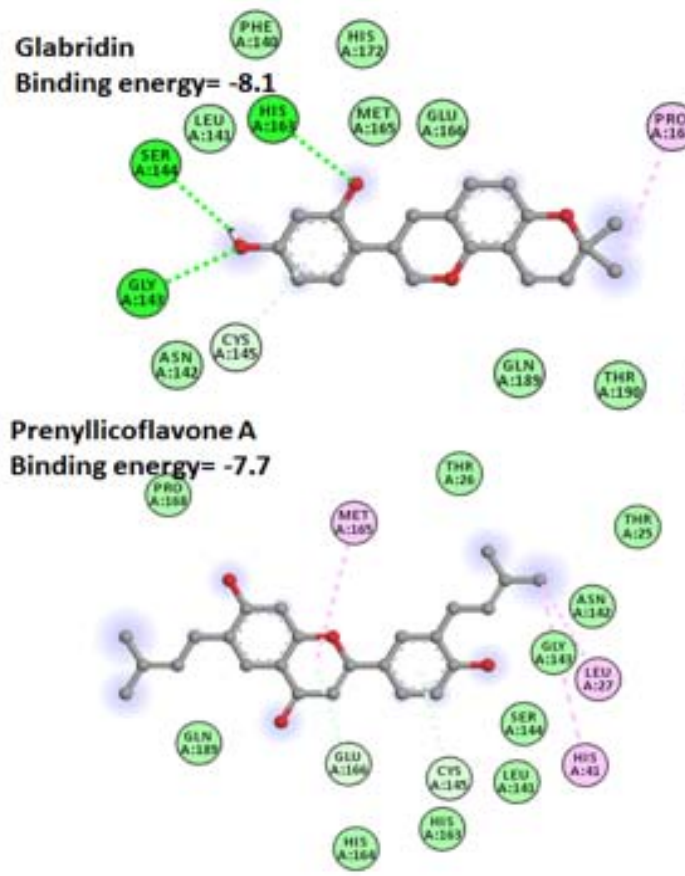

Hispaglabridin A

Glabridin (ค月. (SER

(19.)

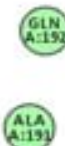

(A149)

\section{Licochalcone A}

Binding energy $=-7.9$

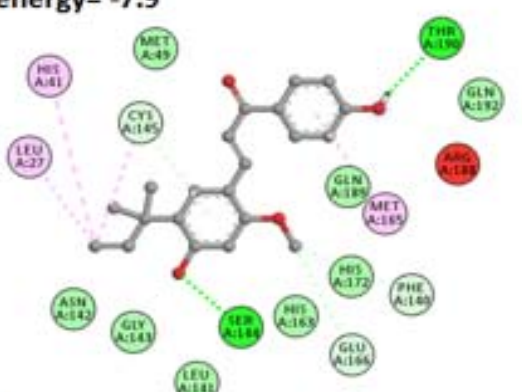

Apioside

(iiii)

Binding energy $=-7.9$

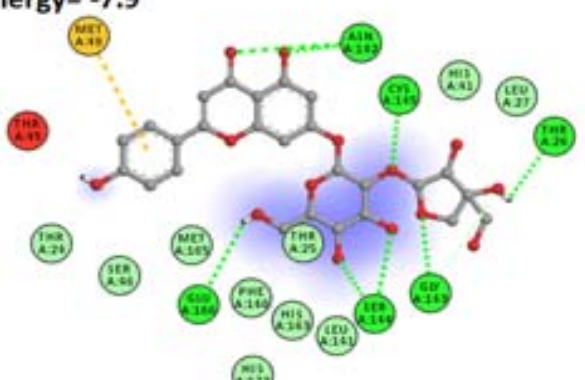

(iiiv)
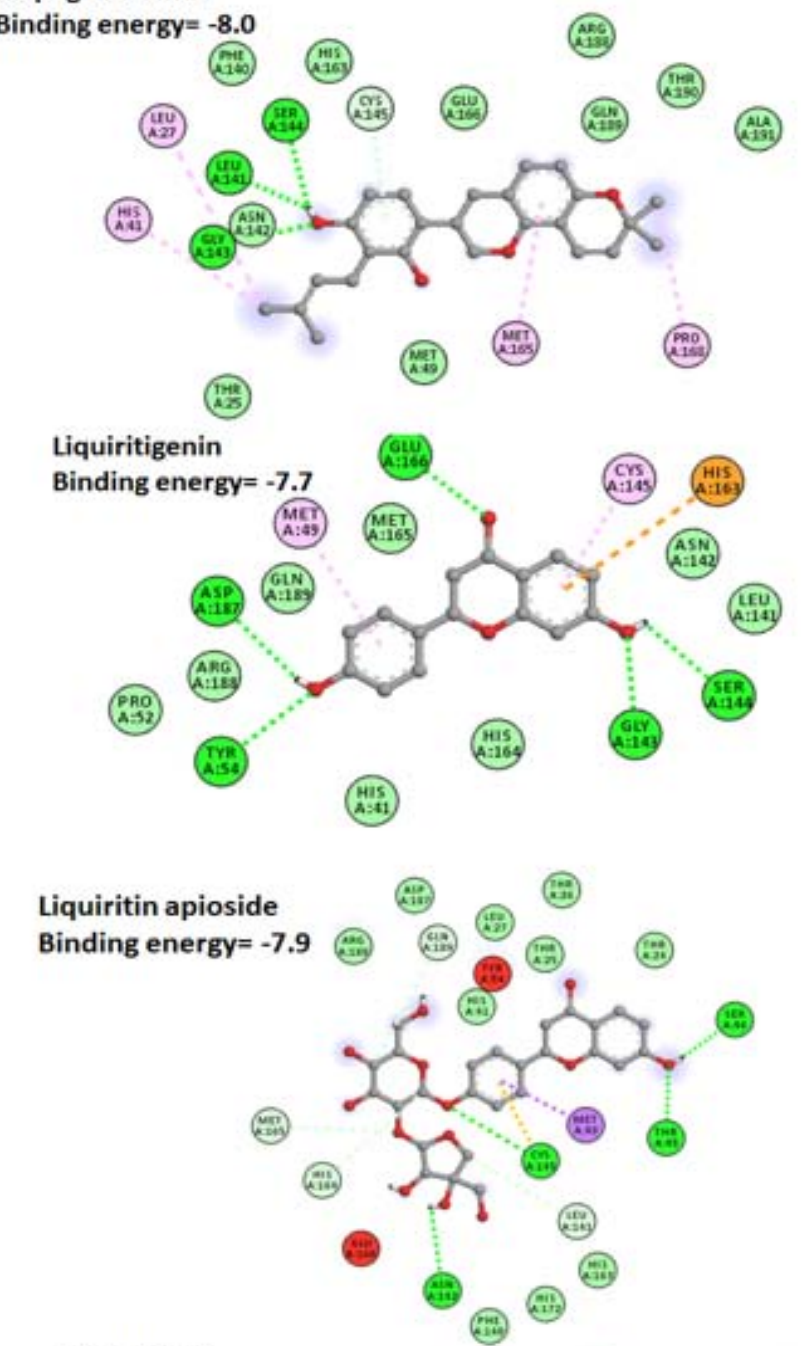

Isoliquiritin Binding energy $=-7.5$

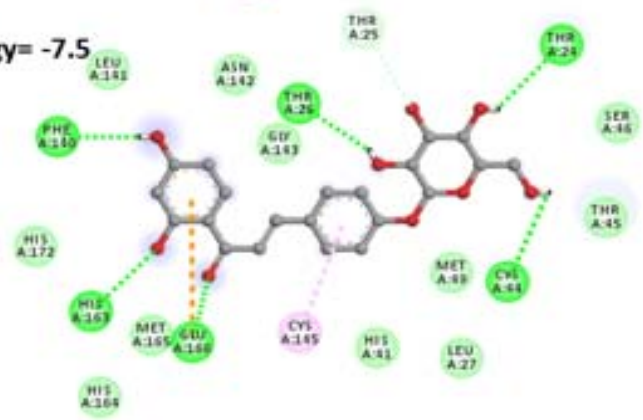

Figure 4b: The predicted binding and 2D interaction of selected phytochemicals from Yashtimadhu against SARS-CoV-2 Mpro (PDB ID: 6LU7) and their different protein residues which are involved in the interaction.

contributed positively for Glycyrrhizin. As for interaction between RdRp with Glycyrrhetic acid is concern both polar solvation and electrostatic energy was unfavourable. Binding energy obtained from MM/PBSA calculation corroborated positively for spike protein with the findings of molecular docking study. Binding free energy obtained by the MM/PBSA calculation for Glycyrrhizin and Glycyrrhetic acid interaction with RdRp was not agreeing with the energy obtained from the molecular docking possible because of unfavourable polar solvation and electrostatic energy contributions.

\section{In-silico anti-viral property}

Web-sever based anti-viral prediction data for Yashtimadhu are shown in Table 3. From the table 3 it is clear that phytochemicals Apioside, Glycyrrhizin, Liquiritigenin, Liquiritin, Prenyllicoflavone A, and Shinflavanone have predicted antiviral property more than 50 for the general viruses. Glabrin A, Glycyrrhizin, Isoliquiritin, 


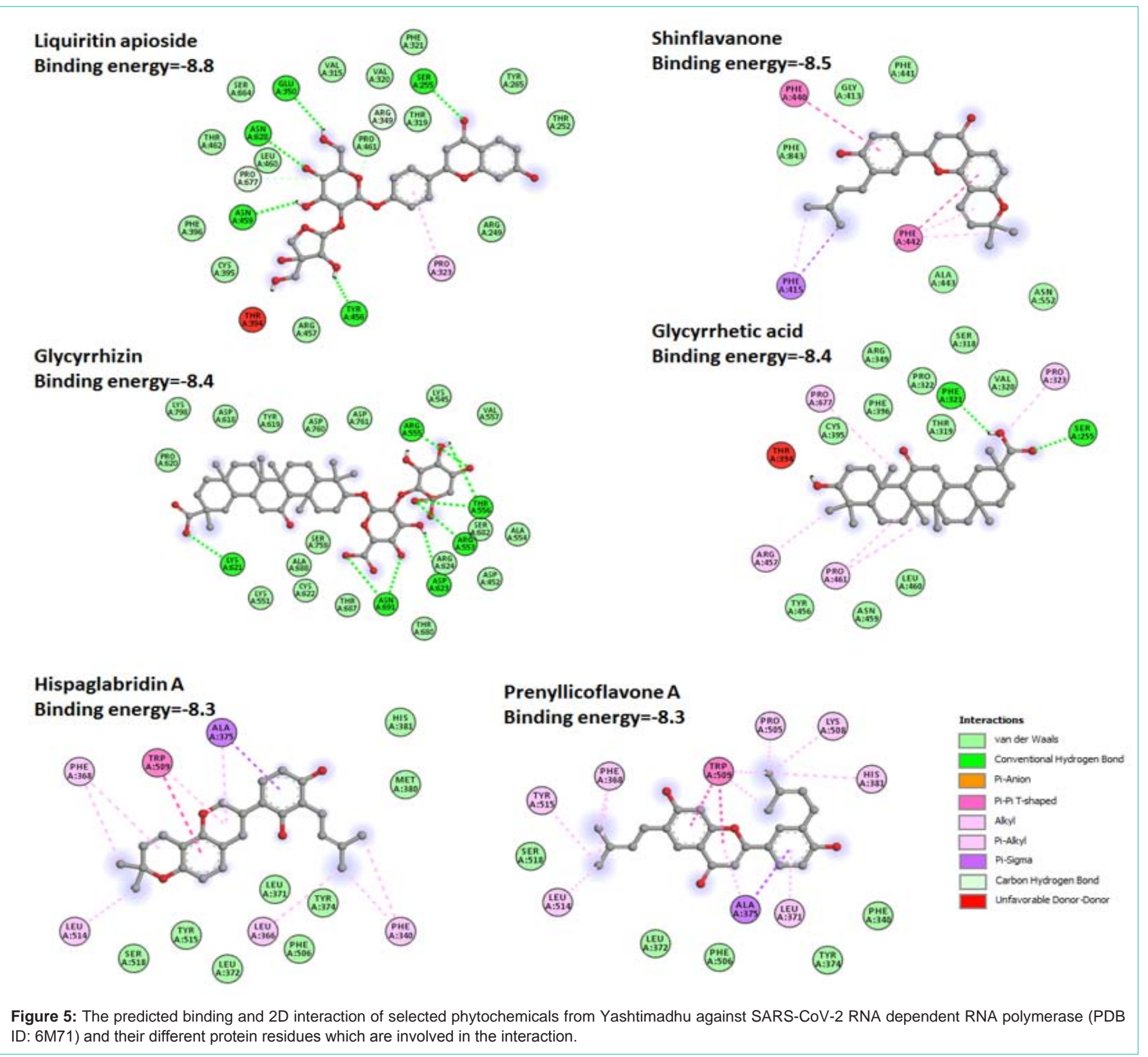

Prenyllicoflavone A, and Salicyclic Acid have predicted value more than 50 for HCV,

Licochalcone A is effective against HHV, whereas Abscisic acid, Glabridin, Glycyrrhetic acid, Isoliquiritigenin, Isoliquiritin, Liquiritin, Prenyllicoflavone A, Salicyclic Acid, Shinflavanone, and Shinpterocarpin are effective against HIV.

\section{In-silico drug-likeness, pharmaceutical characterization and pharmacokinetics}

The phytochemicals which bind to all the selected studied molecules such as SARS-CoV-2 spike, Mpro, RdRp and human ACE2 \& Furin were analysed for their in-silico drug-likeness and pharmacokinetics using pkCSM server [35] (Table 4).

Some of the phytochemicals do not follow the Lipinski's rule of five for all the parameters. ADMET properties calculated with the aid of pkCSM server shows that predicted intestinal absorption of the phytochemicals such as Glabridin, Glycyrrhetic acid, Hispaglabridin A, Prenyllicoflavone A, Shinflavanone, Shinpterocarpin and Isoliquiritigenin are high i.e. 94.164, 100, 92.325, 92.154, 93.109, 96.183 and $91.096 \%$ respectively. Except Glabrin B none of the studied phytochemicals predicted to have hepatotoxicity (Table 4).

\section{Network biology}

A total of 58 target proteins were found to be modulated by phytochemicals present in the Yashtimadhu. Out of them 38 proteins were upregulated whereas 20 were downregulated. Using these affected target proteins a PPI network was created using Cytoscape (Figure 9) and different GO processes and KEGG pathways influenced by these modulated proteins are presented in Table 5 and 6 respectively. Gene ontology analysis shows that top 5 GO processes and KEGG pathways which scored low false discovery rate by upregulated 

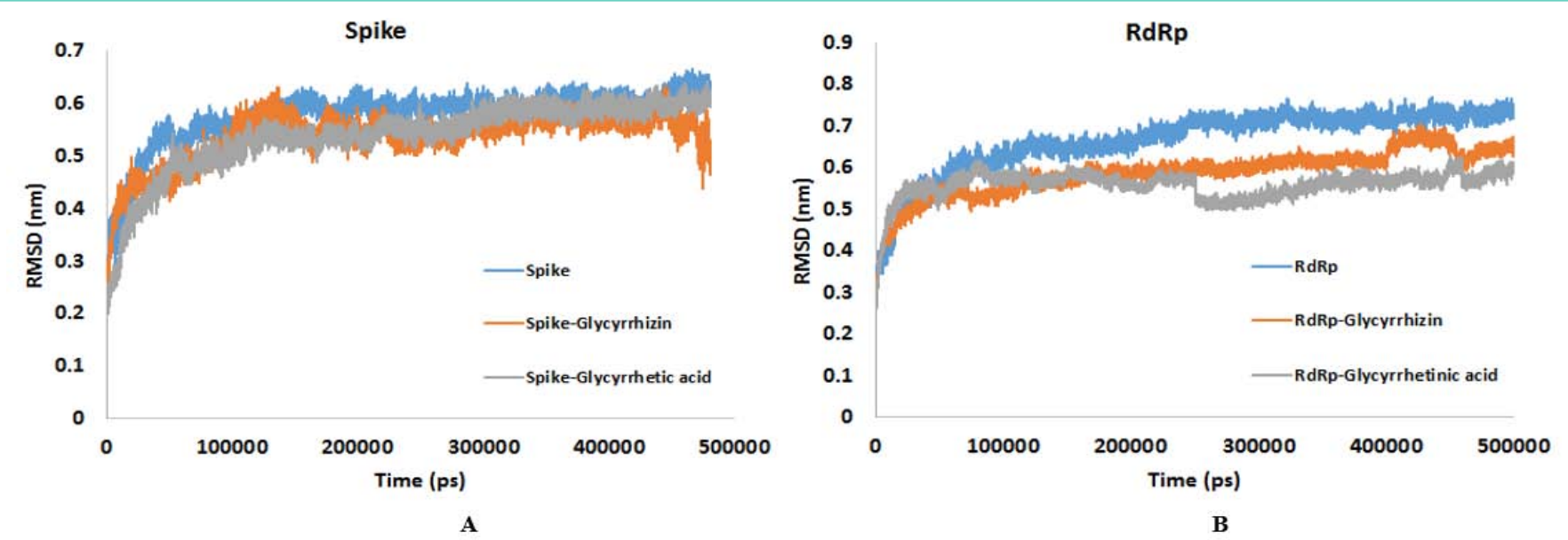

A

Figure 6: RMSD profile of MD simulation for Glycyrrhizin and Glycyrrhetic acid complexed with SARS-CoV-2 proteins. A) Spike (B) RdRp.
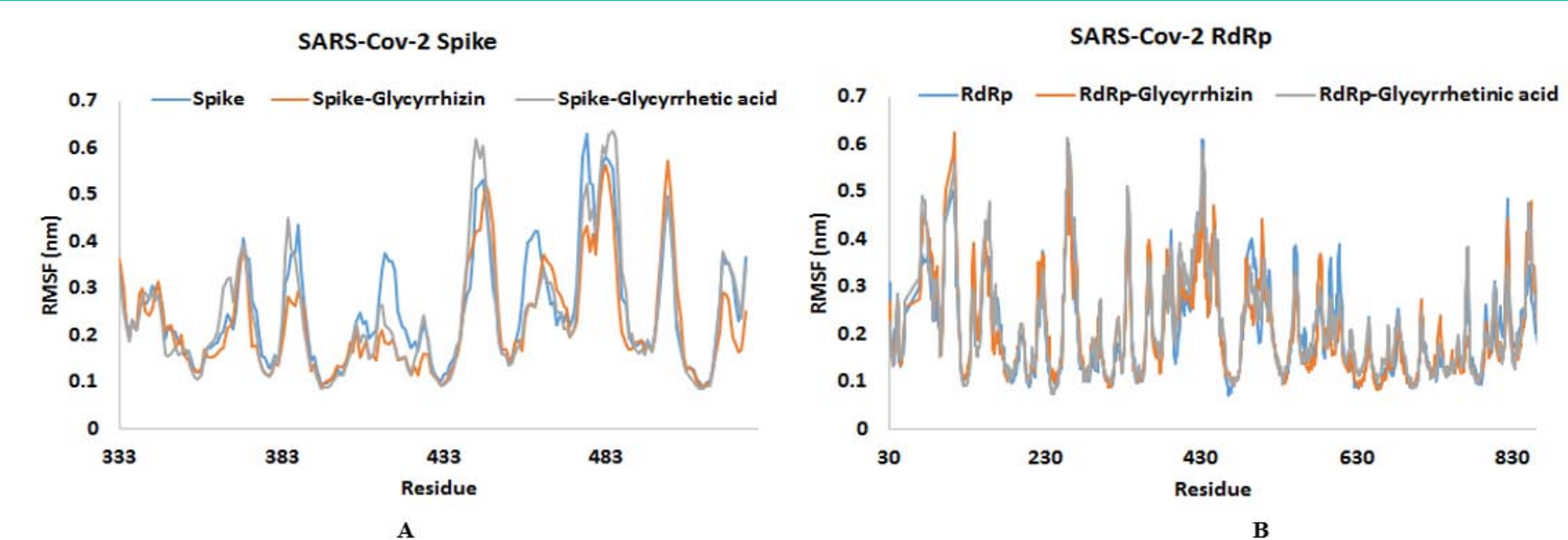

A

Figure 7: RMSF profile of MD simulation for Glycyrrhizin and Glycyrrhetic acid complexed with SARS-CoV-2 proteins. A) Spike (B) RdRp.

Table 2: MM-PBSA binding free energy for Glycyrrhizin and Glycyrrhetic acid with SARS-CoV-2 Spike and RdRp.

\begin{tabular}{|c|c|c|c|c|c|c|c|c|}
\hline \multirow{4}{*}{ Energies } & \multicolumn{8}{|c|}{$\mathrm{kJ} / \mathrm{mol}$} \\
\hline & \multicolumn{4}{|c|}{ Glycyrrhizin } & \multicolumn{4}{|c|}{ Glycyrrhetic acid } \\
\hline & \multicolumn{2}{|c|}{ Spike } & \multicolumn{2}{|c|}{ RdRp } & \multicolumn{2}{|c|}{ Spike } & \multicolumn{2}{|c|}{ RdRp } \\
\hline & Mean & S.E.M. & Mean & S.E.M. & Mean & S.E.M. & Mean & S.E.M. \\
\hline van der Waal energy & -35.49 & 5.64 & -110.74 & 10.25 & -25.02 & 5.64 & -88.27 & 9.25 \\
\hline Electrostatic energy & -191.48 & 31 & -143.24 & 25.5 & -80.61 & 11.29 & 20.69 & 16.09 \\
\hline Polar solvation energy & 115.156 & 25.7 & 407.69 & 31.43 & 56.05 & 12.76 & 104.05 & 18.88 \\
\hline SASA energy & -4.875 & 0.94 & -14.17 & 1.3 & -3.09 & 0.62 & -9.98 & 1.01 \\
\hline Binding energy & -116.69 & 11.77 & 139.53 & 16.63 & -52.67 & 2.87 & 26.49 & 13.05 \\
\hline
\end{tabular}

targets are, regulation of cellular catabolic process, cellular response to cytokine stimulus, inflammatory response, cellular response to organic substance \& defense response, and HIF-1 signaling pathway, Hepatitis B, FoxO signaling pathway, JAK-STAT signaling pathway \& pathways in cancer, respectively. Similarly, top 5 GO processes and KEGG pathways which scored low false discovery rate by downregulated targets are, response to abiotic stimulus, response to hypoxia, cellular response to hypoxia, regulation of transcription from RNA polymerase II promoter in response to stress \& positive regulation of nitrogen compound metabolic process and thyroid hormone signaling pathway, pathways in cancer, prostate cancer, Kaposi's sarcoma-associated herpes virus infection, \& hepatitis B, respectively.

\section{Discussion}

Traditional herbal medicines are gaining attention as potential alternative sources of therapy for diverse diseases across many countries. Medicinal plants and natural products are being accepted 
Table 3: Predicted antiviral property of Yashtimadhu (Glycyrrhizia glabra).

\begin{tabular}{|c|c|c|c|c|c|}
\hline Phytochemicals & General & HBV & HCV & HHV & HIV \\
\hline Abscisic acid & 26.812 & 24.906 & 38.018 & 34.664 & 55.516 \\
\hline Apioside & 51.687 & 18.829 & 48.857 & 44.681 & 38.066 \\
\hline beta-Sitosterol & 42.473 & 16.748 & 39.98 & 34.526 & 45.483 \\
\hline Glabridin & 35.673 & 21.09 & 43.948 & 27.091 & 58.516 \\
\hline Glabrin A & 42.703 & 16.748 & 53.493 & 34.526 & 45.634 \\
\hline Glycyrrhetic acid & 47.547 & 20.958 & 30.471 & 41.567 & 70.042 \\
\hline Glycyrrhizin & 52.606 & 17.526 & 79.505 & 46.135 & 47.457 \\
\hline Hispaglabridin A & 48.873 & 17.681 & 34.993 & 42.659 & 33.287 \\
\hline Isoliquiritigenin & 24.704 & 20.105 & 19.497 & 24.771 & 86.698 \\
\hline Isoliquiritin & 45 & 14.191 & 67.412 & 27.622 & 55.226 \\
\hline Licochalcone A & 23.012 & 21.691 & 40.332 & 59.741 & 44.864 \\
\hline Liquiritigenin & 45.532 & 12.32 & 51 & 45.109 & 40.789 \\
\hline Liquiritigenin & 74.952 & 20.079 & 32.175 & 29.693 & 33.205 \\
\hline Liquiritin & 52.939 & 13.97 & 39.704 & 36.44 & 57.44 \\
\hline Liquiritin Apioside & 45.532 & 12.32 & 51 & 45.109 & 40.789 \\
\hline Prenyllicoflavone A & 67.049 & 18.705 & 62.488 & 19.52 & 62.725 \\
\hline Salicyclic Acid & 48.135 & 18.96 & 56.327 & 45.27 & 63.173 \\
\hline Shinflavanone & 60.632 & 22.133 & 38.609 & 40.37 & 59.703 \\
\hline Shinpterocarpin & 40.858 & 24.342 & 29.38 & 17.984 & 54.543 \\
\hline & & & & & \\
\hline & & & & \\
\hline
\end{tabular}

widely due to the perception that they may have fewer side effects as compared to synthetic molecules. Use of herbs and phytochemicals has a long history in the management of various respiratory diseases [38-40]. In European countries, several species of herbs have been used against flu and common cold [41]. In India, use of spices and herbs for treatment of various diseases including cough, cold and flu is a common practice with recorded history of several thousands of years [42,43]. Recently, Maurya and Sharma [44], have predicted that phytochemicals found in traditional Indian Ayurvedic Kadha have significant potential to bind with important SARS-CoV-2 proteins and human receptor and may be beneficial in boosting host immunity and managing symptoms of COVID-19 [44]. A number of study were carried out to explore the beneficial effect of different phytochemicals found in the herbs against SARS-CoV-2 using in silico approach. Phytochemicals found in herbs such as Ashwagandha, Tulsi, Giloy, and Turmeric have potential to selectively bind with different SARS-CoV-2 vital targets. Many of the Indian spices and their phytochemicals which are known for their long history for their anti-viral activity were also shown to efficiently bind with the SARS$\mathrm{CoV}-2$ target proteins in the in silico studies.

The Yashtimadhu root has been significantly used for ages in Indian system of Ayurvedic medicine, in ancient Egyptian medicine, and in traditional Chinese medicine [27,45]. It had already been known for its anti-viral properties [46-48]. Yashtimadhu root contains a variety of phytochemicals such as flavonoids like Glycyrrhizin, Liquiritigenin, and Glabridin that had antiviral activity against the SARS coronavirus $[24,49]$. Phytochemicals, triterpenoids found in Yashtimadhu root especially glycyrrhizic acid and glycyrrhetinic acid that were found to be extremely potent against the SARS-CoV $[24,49]$.

The therapeutics which prevent the CoV severity may work on several specific targets such as virus structural proteins which block virus binding with host cell receptors, or inhibiting the virus's selfassembly process (such as spike and nucleocapsid proteins); some may be acting on critical functional proteins and enzymes which prevent the virus RNA synthesis and replication (such as main protease, RdRp and helicase); some act on $\mathrm{CoV}$ virulence factors (such as Nsp1, Nsp3c and ORF7a) and some act on host's specific receptors or enzymes, preventing virus from entering into host's cells (such as ACE2, furin). It is well-known that SARS-CoV viral genome encodes more than 20 proteins, among which two proteases i.e. 3-chymotrypsin-like protease (main protease, Mpro) and papainlike protease (PLpro) are vital for virus replication [50]. They cleave the two translated polyproteins (PP1A and PP1AB) into individual functional components, resulting in release of 16 non-structural proteins (NSPs) [51].

CoVs spike protein is a main glycosylated protein that interacts with the host by binding to host cell receptors to mediate virus invasion and determine viral tissue or host tropism [52]. Spike

Table 4: In-silico ADMET prediction of the selected phytochemicals found in Yashtimadhu.

\begin{tabular}{|c|c|c|c|c|c|c|c|c|c|c|c|}
\hline Phytochemicals & MW & $\log P$ & $\begin{array}{l}\text { No. of } \\
\text { rotatable } \\
\text { bonds }\end{array}$ & $\begin{array}{c}\text { No. of } \\
\text { HBA }\end{array}$ & $\begin{array}{l}\text { No. of } \\
\text { HBD }\end{array}$ & $\begin{array}{c}\text { Water solubility } \\
\text { (log } \mathrm{mol} / \mathrm{L})\end{array}$ & $\begin{array}{c}\text { Intestinal } \\
\text { absorption } \\
\text { (human) } \\
\text { (\% Absorbed) }\end{array}$ & $\begin{array}{c}\text { Total } \\
\text { Clearance } \\
(\log \mathrm{ml} / \\
\mathrm{min} / \mathrm{kg})\end{array}$ & $\begin{array}{l}\text { AMES } \\
\text { toxicity }\end{array}$ & $\begin{array}{c}\text { Max. tolerated } \\
\text { dose } \\
\text { (human) (log } \\
\text { mg/kg/day) }\end{array}$ & Hepatotoxicity \\
\hline Apioside & 564.5 & -1.485 & 7 & 14 & 8 & -2.851 & 17.411 & -0.054 & No & 0.446 & No \\
\hline Glabridin & 324.4 & 4.001 & 1 & 4 & 2 & -3.646 & 94.164 & 0.121 & No & -0.395 & No \\
\hline Glabrin B & 835 & -2.554 & 8 & 11 & 9 & -2.93 & 10.645 & 10.645 & No & 0.491 & Yes \\
\hline Glycyrrhizin & 822.9 & 2.246 & 7 & 13 & 8 & -2.892 & 0 & -0.304 & No & 0.389 & No \\
\hline Hispaglabridin A & 392.5 & 5.509 & 3 & 4 & 2 & -4.649 & 92.326 & 0.41 & No & 0.019 & No \\
\hline Liquiritin & 418.4 & 0.277 & 4 & 9 & 5 & -3.354 & 46.076 & 0.342 & Yes & 0.186 & No \\
\hline Prenyllicoflavone A & 390.5 & 5.889 & 5 & 4 & 2 & -4.57 & 92.154 & 0.399 & Yes & -0.017 & No \\
\hline Shinflavanone & 390.5 & 5.792 & 3 & 4 & 1 & -6.226 & 93.109 & 0.58 & No & 0.489 & No \\
\hline Liquiritin apioside & 550.5 & -1.258 & 1 & 13 & 7 & -3.103 & 18.25 & 0.436 & No & 0.055 & No \\
\hline Isoliquiritigenin & 256.3 & 2.7 & 3 & 4 & 3 & -3.06 & 91.096 & 0.087 & No & 0.118 & No \\
\hline
\end{tabular}




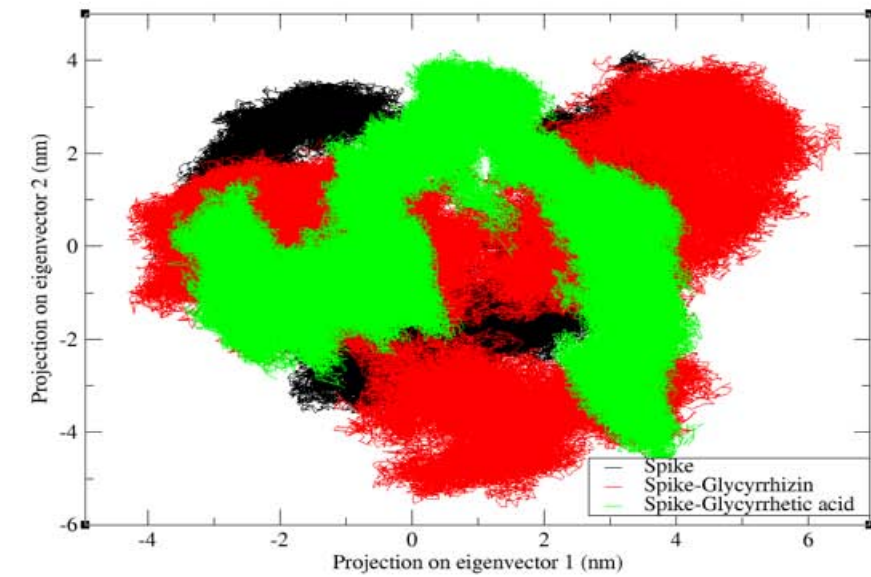

A. Spike

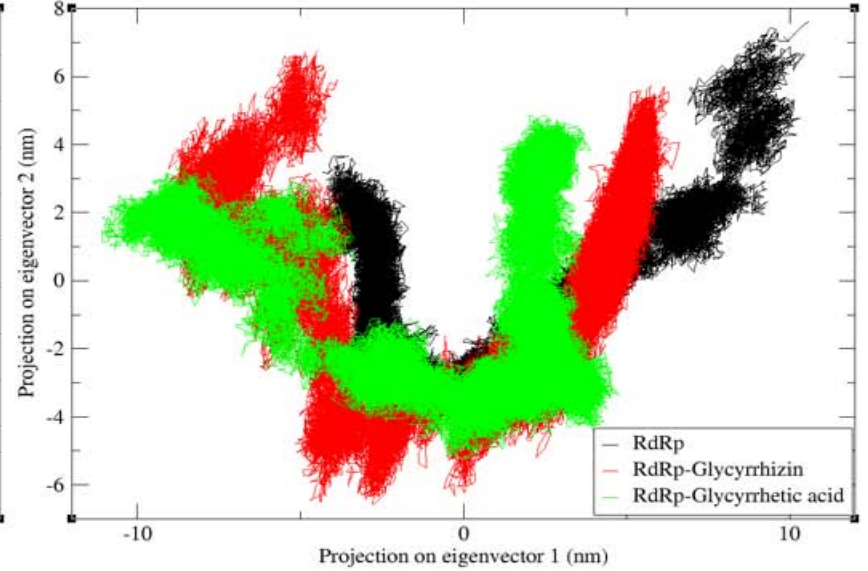

B. $R d R p$

Figure 8: Principle component analysis for projection of the motion of the protein (Spike and RdRp) in phase space along the first two principal eigenvectors. The eigenvalues plotted against the corresponding eigenvector indices obtained from the Ca covariance matrix constructed from full MD trajectory.

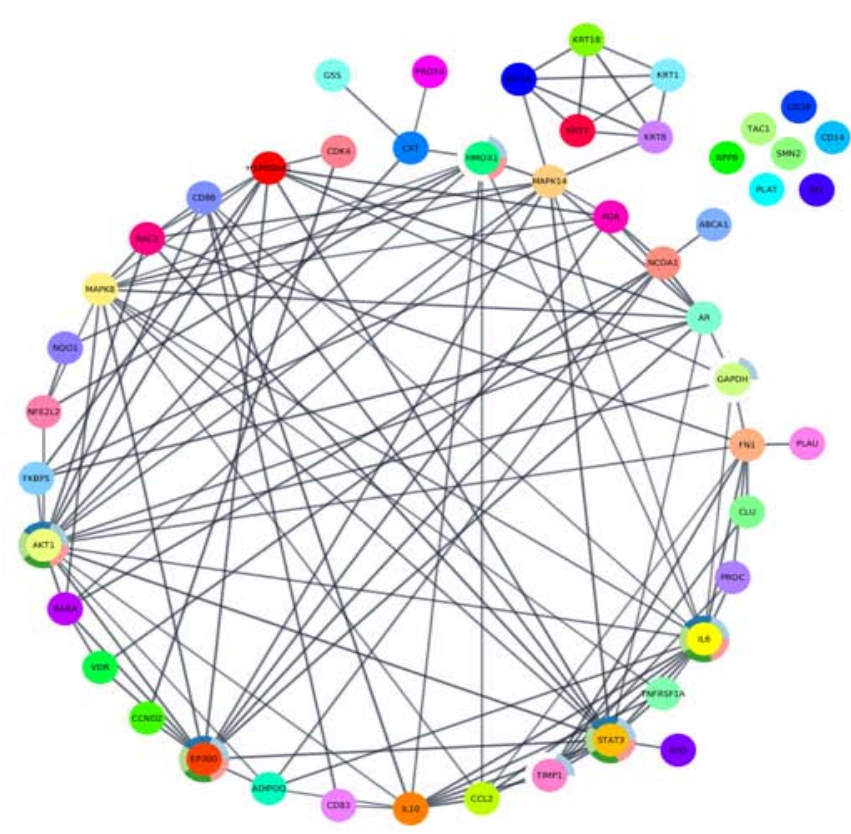

A. Upregulated Network

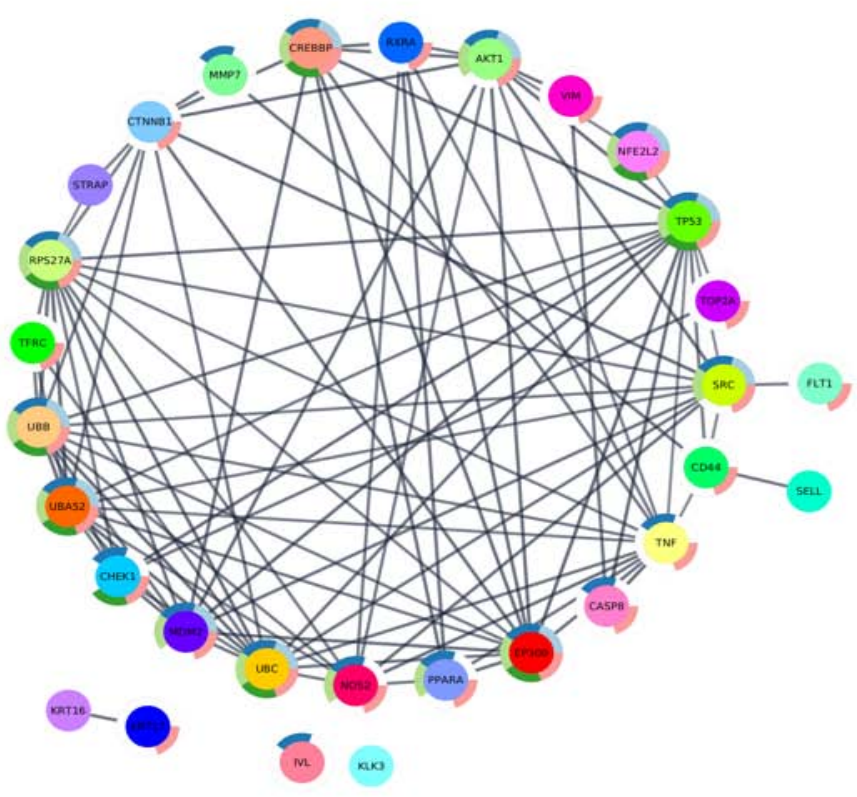

B. Downregulated Network

Figure 9: Protein-protein interaction network for upregulated and downregulated target protein for the phytochemicals of Yashtimadhu.

protein is the main structural protein of CoVs and assembles into a special corolla structure on the surface of the virus as a trimer. The host ACE2 has been proved by many studies to be the specific receptor for the spike Receptor Binding Domain (RBD) of SARS$\mathrm{CoV}$. Spike of $\mathrm{CoV}$ is cleaved into $\mathrm{S} 1$ and $\mathrm{S} 2$ by the host cell protease furin during infection. The modified spike glycoprotein can interact with the cell surface receptor ACE2. The S1 subunit, which contains the RBD, binds with host cell surface receptors, and the S2 subunit mediates virus-cell and cell-cell membrane fusion. Initial interactions between the S1 domain and its host receptor (ACE2), and subsequent S2 segment mediated fusion of the host and viral membrane allows the viral RNA genome to enter inside the host cells. Thus, these proteins represent as important targets for designing drug (Li 2016). Spike structural integrity and cleavage activation play a key role in virus invasion and virulence.

Very recently, Wang et al. [53] presented the crystal structure of the C-terminal domain of SARS-CoV-2 spike protein in complex with human ACE2 and reported that amino acid residues S19, Q24, T27, F28, D30, K31, H34, E35, E37, D38, Y41, Q42, L45, L79, M82, Y83, N330, K353, G354, D355 and R357 of the human ACE2 interact with amino acid residues K417, G446, Y449, Y453, L455, F456, Y473, A475, G476, E484, F486, N487, Y489, F490, Q493, G496, Q498, T500, N501, G502 and Y505 of C-terminal domain of SARS-CoV-2 spike protein [53]. Our study shows that different phytochemicals 
Table 5: List of top $5 \mathrm{GO}$ process influence by upregulated and downregulated targets of Yashtimadhu.

\begin{tabular}{|c|c|c|c|c|c|}
\hline Targets & $\begin{array}{l}\text { GO process } \\
\text { ID }\end{array}$ & GO Process & $\begin{array}{c}\text { False } \\
\text { discovery } \\
\text { rate }\end{array}$ & $\begin{array}{l}\text { No. of } \\
\text { targets }\end{array}$ & Name of targets \\
\hline \multirow{5}{*}{$\begin{array}{l}\text { Upregulated } \\
\text { targets }\end{array}$} & GO.0031329 & $\begin{array}{l}\text { Regulation of cellular catabolic } \\
\text { process }\end{array}$ & 3.34E-05 & 6 & HMOX1, TIMP1, GAPDH, EP300, STAT3, AKT1 \\
\hline & GO.0071345 & $\begin{array}{l}\text { Cellular response to cytokine } \\
\text { stimulus }\end{array}$ & 4.89E-05 & 6 & HMOX1, TIMP1, GAPDH, STAT3, IL6, AKT1 \\
\hline & GO.0006954 & Inflammatory response & $6.04 \mathrm{E}-05$ & 5 & HMOX1, TIMP1, STAT3, IL6, AKT1 \\
\hline & GO.0071310 & $\begin{array}{l}\text { Cellular response to organic } \\
\text { substance }\end{array}$ & $6.52 \mathrm{E}-05$ & 7 & HMOX1, TIMP1, GAPDH, EP300, STAT3, IL6, AKT1 \\
\hline & GO.0006952 & Defense response & $9.69 \mathrm{E}-05$ & 6 & HMOX1, TIMP1, GAPDH, STAT3, IL6, AKT1 \\
\hline \multirow{5}{*}{$\begin{array}{l}\text { Downregulated } \\
\text { targets }\end{array}$} & GO.0009628 & Response to abiotic stimulus & $4.71 \mathrm{E}-13$ & 18 & $\begin{array}{c}\text { MDM2, MMP7, CREBBP, EP300, TP53, RPS27A, UBB, NOS2, } \\
\text { CASP8, IVL, } \\
\text { SRC, NFE2L2, PPARA, UBA52, CHEK1, TNF, UBC, AKT1 }\end{array}$ \\
\hline & GO.0001666 & Response to hypoxia & $4.71 \mathrm{E}-13$ & 13 & $\begin{array}{c}\text { MDM2, CREBBP, EP300, TP53, RPS27A, UBB, NOS2, SRC, NFE2L2, } \\
\text { PPARA, } \\
\text { UBA52, UBC, AKT1 }\end{array}$ \\
\hline & GO.0071456 & Cellular response to hypoxia & $4.71 \mathrm{E}-13$ & 11 & $\begin{array}{l}\text { MDM2, CREBBP, EP300, TP53, RPS27A, UBB, SRC, NFE2L2, } \\
\text { UBA52, UBC, AKT1 }\end{array}$ \\
\hline & GO.0043618 & $\begin{array}{c}\begin{array}{c}\text { Regulation of transcription from RNA } \\
\text { polymerase II promoter in response } \\
\text { to stress }\end{array} \\
\end{array}$ & $5.47 \mathrm{E}-13$ & 9 & $\begin{array}{c}\text { CREBBP, EP300, TP53, RPS27A, UBB, NFE2L2, UBA52, CHEK1, } \\
\text { UBC }\end{array}$ \\
\hline & GO.0051173 & $\begin{array}{l}\text { Positive regulation of nitrogen } \\
\text { compound metabolic process }\end{array}$ & $1.25 \mathrm{E}-12$ & 24 & $\begin{array}{c}\text { MDM2, CREBBP, EP300, TP53, RPS27A, FLT1, UBB, KRT17, NOS2, } \\
\text { CTNNB1, CASP8, TFRC, SRC, NFE2L2, PPARA, UBA52, CHEK1, } \\
\text { CD44, TNF, TOP2A, RXRA, UBC, VIM, AKT1 }\end{array}$ \\
\hline
\end{tabular}

Table 6: List of top 5 KEGG pathways influence by upregulated and downregulated targets of Yashtimadhu.

\begin{tabular}{|c|c|c|c|c|c|}
\hline Targets & $\begin{array}{c}\text { KEGG } \\
\text { Pathways }\end{array}$ & Pathways & $\begin{array}{c}\text { False } \\
\text { discovery rate }\end{array}$ & $\begin{array}{l}\text { No. of } \\
\text { Targets }\end{array}$ & Name of target \\
\hline \multirow{5}{*}{$\begin{array}{l}\text { Upregulated } \\
\text { targets }\end{array}$} & hsa04066 & HIF-1 signalling pathway & 1.27E-14 & 7 & HMOX1, TIMP1, GAPDH, EP300, STAT3, IL6, AKT1 \\
\hline & hsa05161 & Hepatitis B & 4.41E-06 & 4 & EP300, STAT3, IL6, AKT1 \\
\hline & hsa04068 & FoxO signalling pathway & 4.41E-06 & 4 & EP300, STAT3, IL6, AKT1 \\
\hline & hsa04630 & Jak-STAT signalling pathway & 4.97E-06 & 4 & EP300, STAT3, IL6, AKT1 \\
\hline & hsa05200 & Pathways in cancer & $6.37 \mathrm{E}-06$ & 5 & HMOX1, EP300, STAT3, IL6, AKT1 \\
\hline \multirow{5}{*}{$\begin{array}{l}\text { Downregulated } \\
\text { targets }\end{array}$} & hsa04919 & Thyroid hormone signalling pathway & 1.64E-09 & 8 & $\begin{array}{c}\text { MDM2, CREBBP, EP300, TP53, CTNNB1, SRC, RXRA, } \\
\text { AKT1 }\end{array}$ \\
\hline & hsa05200 & Pathways in cancer & 1.33E-08 & 11 & $\begin{array}{l}\text { MDM2, CREBBP, EP300, TP53, KLK3, NOS2, CTNNB1, } \\
\text { CASP8, NFE2L2, RXRA, AKT1 }\end{array}$ \\
\hline & hsa05215 & Prostate cancer & 1.33E-08 & 7 & MDM2, CREBBP, EP300, TP53, KLK3, CTNNB1, AKT1 \\
\hline & hsa05167 & $\begin{array}{l}\text { Kaposi's sarcoma-associated } \\
\text { herpesvirus infection }\end{array}$ & $1.40 \mathrm{E}-08$ & 8 & CREBBP, EP300, TP53, UBB, CTNNB1, CASP8, SRC, AKT1 \\
\hline & hsa05161 & Hepatitis B & 7.35E-08 & 7 & CREBBP, EP300, TP53, CASP8, SRC, TNF, AKT1 \\
\hline
\end{tabular}

found in the Yashtimadhu have significant binding affinity with viral spike, host ACE2 \& furin proteins (Figure 1-3). Phytochemical found in Yashtimadhu, interact with few of these amino acid residues or the residues which are lying near to them. This indicates that phytochemicals found in the Yashtimadhu can interfere with the interaction of the virus with the host cells and can slow down the viral entry. The spike protein is also known to activate the immune response of the host cell towards CoVs [52]. The S1 domain of spike acts as a major antigen on the surface of the virus [54]. Binding of the phytochemicals with the spike may also minimize the immune response mediated by it.

SARS-CoV-2 Mpro is also considered as a promising druggable target because it plays vital role in viral gene expression and replication and are crucial for maturation cleavage events of viral precursor polyprotein. The functional form of Mpro is a dimer of two protomers and each protomer has three domains i.e. domain I, II, and III and the binding site is located at the cleft between domains I and II. Residues His41 and Cys145 of Mpro form the catalytic dyad.
Our study shows that many of the phytochemicals have displayed the significant binding affinity with the SARS-CoV-2 Mpro and have significant interaction with His41 and Cys145 residues (Figure 4a and $4 b)$.

The RNA-dependent RNA polymerase is the central module of CoVs replication/transcription machinery and an excellent target for new therapeutics development. RdRp, catalyses the synthesis of viral RNA and thus plays a central role in the replication and transcription cycle of SARS-CoV-2 in association with nsp7 and nsp8 as co-factors. Co-factor snsp7 and nsp8 are essential for proper functioning of the RdRp. Our docking study shows that many of the phytochemicals found in the Yashtimadhu bind on the interface region of the nsp12 where nsp7 or nsp8 co-factor binds (Figure 5). This indicates that the binding of the phytochemical can slow down the RdRp activity resulting in decrease in the virulence.

Studies employing molecular docking only provides information about the static poses of the most preferred conformations of a ligand in the binding pocket of a protein. So it is essential to validate the 
molecular docking results with the MD simulation. MD simulation study is based on the classical Newtonian physics and give information about the actual movement and structural perturbations of a protein in its biological environment. MD simulation provide information about the stability of binding pose. MD simulation performed for spike and RdRp protein complexed with either Glycyrrhizin or Glycyrrhetic acid well corroborated with the molecular docking study. RMSD and RMS graph shows that the interaction of Glycyrrhizin and Glycyrrhetic acid is quiet stable (Figure 6) with minimum fluctuation (Figure 7). For getting more insight, MD trajectories were used for the PCA analysis to investigate and explore the global motion of a protein during the simulation. Our PCA study showed that both spike and RdRp protein complexed with Glycyrrhizin or Glycyrrhetic acid have lower phase space compared to unbound proteins indicating more stability of the complex during the simulation (Figure 8). Thus, our MD simulation study corroborated well with the findings of the molecular docking. Further MD trajectories were used for the calculation of the thermodynamic of the protein-ligand complex for determining the free binding energy employing g_mmpbsa package [33]. The final binding energy for Spike protein complexed with Glycyrrhizin and Glycyrrhetic acid obtained from MM/PBSA calculation was in good agreement with the findings of molecular docking study (Table 2). Binding free energy obtained for Glycyrrhizin and Glycyrrhetic acid interaction with RdRp was not agreeing with the energy obtained from the molecular docking possible because of unfavourable polar solvation and electrostatic energy contributions.

In silico anti-viral prediction study indicate that many of the phytochemical found in the Yashtimadhu have very effective antiviral property for general viruses along with the well-known HIV virus (Table 3). Our in-silico drug-likeness and pharmacokinetic prediction study shows that many of the active phytochemicals found in the Yashtimadhu such as Glabridin, Glycyrrhetic acid, Hispaglabridin A, Prenyllicoflavone A, Shinflavanone, Shinpterocarpin and Isoliquiritigenin do not have any predicted hepatotoxicity and show very high $(>90 \%)$ intestinal absorption (Table 4$)$. This indicates that after consumption of Yashtimadhu the active phytochemicals will be absorbed and can interact with the viral spike, Mpro and other proteins along with the human receptor and proteins needed by $\mathrm{CoV}$ during infection.

Network biology is an emerging area to predict the possible targets of the phytochemicals and prediction of their PPI interaction and the pathways influence by it. So to predict the possible targets and the molecular pathways phytochemicals present in the Yashtimadhu were subjected for the network biology study. Our study shows that it significantly influences the different GO processes and the pathways which are involved in the modulation of the immune systems (Figure 9). Upregulation of pathways and process related to hypoxia, FoxO subfamily of forkhead (Fox) and Janus kinase (JAK)signal transducer and activator of transcription (STAT) pathway have significant role in the modulation of the immunity. Study have shown that hypoxia play important role in the regulation of many innate immune functions such as cell migration, apoptosis, phagocytosis of pathogens, antigen presentation and production of cytokines, chemokines, and angiogenic and antimicrobial factors [55]. Similarly, the FoxO subfamily of forkhead (Fox) transcription factors play critical roles in the homeostasis of immune cells, including $\mathrm{T}$ cells,
B cells, neutrophils and other non-lymphoid lineages that modulate inflammation. FOXO transcription factors have been found to play critical roles in regulation of proliferation, apoptosis and control of oxidative stress [56]. The JAK-STAT pathway plays critical roles in orchestrating of immune system, especially cytokine receptors and they can modulate the polarization of $\mathrm{T}$ helper cells and responsible for mediating signals of over fifty cytokines, growth factors and hormones [57].

During the SARS-CoV infection, human lung epithelial cells are among the first targets for viral entry. In response to viral multiplication and host cell damage, lung epithelial cells secrete inflammatory mediators to initiate and exacerbate host innate inflammatory responses, causing detrimental immune-mediated pathology within the lungs in certain cases. In a very recent study, Huang et al. [58] have shown that the patients infected with SARSCoV-2 had high amounts of IL1 $\beta$, IFN $\gamma$, IP10, and MCP1, which can mediate cytokine storm associated multi-organ damage. At the same time, SARS-CoV-2 infection also initiates increased secretion of T-helper-2 (Th2) cytokines (e.g, IL4 and IL10) which suppress inflammation [58]. The increased secretion of inflammatory mediators was also associated with moderation of helper $\mathrm{T}$ cell responses in COVID-19 patients. Zhang et al. [59] shared their experience about the anti-inflammation treatment of patients with severe COVID-19 and described the importance of anti-inflammatory drugs for the treatment in patients suffering from symptoms including multiple organ failure and Acute Respiratory Distress Syndrome (ARDS) [59]. There are several reports showing that Yashtimadhu and its phytochemicals have significant anti-inflammatory property [19-22]. Our study predicts that many of the phytochemicals such as Apioside, Beta-sitosterol, Glabridin, Glabrin B, Glycyrrhetic acid, Glycyrrhizin, Hispaglabridin A, Isoliquiritin, Licochalcone A, Liquiritigenin, Liquiritin apioside, Liquiritin, Prenyllicoflavone A, Shinflavanone, Shinpterocarpin and Stigmasterol found in Yashtimadhu, have significant binding affinity with more than two inflammatory mediators (Supplementary Table 1). This indicates Yashtimadhu may reduce the inflammatory response and will boost the immunity of the host will be also helpful in the decreasing the severity of ARDS. However, this molecular docking study needs further validation by in vitro and in vivo experiments. Formation of the thrombotic clot is one of the major post COVID-19 problems. Study have shown that Glycyrrhizin present in Yashtimadhu possess antithrombotic property so it use will be beneficial in the managing post COVID-19 complications [60].

\section{Conclusion}

In conclusion, molecular docking, MD simulation, pharmacokinetics, toxicity and network biology studies shows that usage of Yashtimadhu may be beneficial in prevention of SARS-CoV-2 infection and also reducing the severity in the infected person. In silico ADMET prediction studies shows that usage of Yashtimadhu is safe. Thus in consultation with Ayurvedic practitioner, Yashtimadhu can be taken as immunity booster and also as prophylaxis in prevention and management of COVID-19 and associated complications.

\section{Acknowledgement}

The author would like to thank Dr. S. Santosh Kumar, Radiation Biology \& Health Sciences Division, Bhabha Atomic Research Centre, 
Mumbai for his valuable constructive suggestions and critical review of the article.

\section{References}

1. Corman VM, Muth D, Niemeyer D \& Drosten C. Hosts and Sources of Endemic Human Coronaviruses. Adv Virus Res. 100: 163-188.

2. Paules $\mathrm{Cl}$, Marston HD \& Fauci AS. Coronavirus Infections-More Than Just the Common Cold. JAMA. 2020.

3. Zhou Y, Hou Y, Shen J, Huang Y, Martin W \& Cheng F. Network-based drug repurposing for novel coronavirus 2019-nCoV/SARS-CoV-2. Cell Discovery. 2020; 6: 14.

4. Zhang H, Penninger JM, Li Y, Zhong N \& Slutsky AS. Angiotensin-converting enzyme 2 (ACE2) as a SARS-CoV-2 receptor: molecular mechanisms and potential therapeutic target. Intensive Care Medicine. 2020; 46: 586-590.

5. Vankadari N. Structural interactions between pandemic SARS-CoV-2 spike glycoprotein and human Furin protease. BioRxiv. 2020

6. Salata C, Calistri A, Parolin C \& Palù G. Coronaviruses: a paradigm of new emerging zoonotic diseases. Pathogens and Disease. 2020; 77

7. Ye Z-W, Yuan S, Yuen K-S, Fung S-Y, Chan C-P \& Jin D-Y. Zoonotic origins of human coronaviruses. International journal of biological sciences. 2020 16: $1686-1697$

8. Wu C, Liu Y, Yang $Y$, Zhang $P$, Zhong $W$, Wang $Y$, et al. Analysis of therapeutic targets for SARS-CoV-2 and discovery of potential drugs by computational methods. Acta Pharmaceutica Sinica B. 2020.

9. Badiani AA, Patel JA, Ziolkowski K \& Nielsen FBH. Pfizer: The miracle vaccine for COVID-19? Public Health in Practice. 2020; 1: 100061-100061.

10. Baden LR, El Sahly HM, Essink B, Kotloff K, Frey S, Novak R, et al. Efficacy and Safety of the mRNA-1273 SARS-CoV-2 Vaccine. N Engl J Med. 2021 384: 403-416.

11. Rawat K, Kumari P \& Saha L. COVID-19 vaccine: A recent update in pipeline vaccines, their design and development strategies. Eur J Pharmacol. 2021; 892: 173751

12. Cusinato J, Cau Y, Calvani AM \& Mori M. Repurposing drugs for the management of COVID-19. Expert Opinion on Therapeutic Patents. 2021: 1-13.

13. Sultana J, Crisafulli S, Gabbay F, Lynn E, Shakir S \& Trifirò G. Challenges for Drug Repurposing in the COVID-19 Pandemic Era. Frontiers in Pharmacology. 2020: 11

14. Yaghoubi A, Amel Jamehdar S, Movaqar A, Milani N \& Soleimanpour $S$ An effective drug against COVID-19: reality or dream? Expert Review of Respiratory Medicine. 2021; 15: 505-518.

15. Alleva L, Charles C \& Clark IA. Using complementary and alternative medicines to target the host response during severe influenza. EvidenceBased Complementary and Alternative Medicine. 2010; 7: 501-510.

16. Arora R, Chawla R, Marwah R, Arora P, Sharma RK, Kaushik V, et al. Potential of Complementary and Alternative Medicine in Preventive Management of Novel H1N1 Flu (Swine Flu) Pandemic: Thwarting Potential Disasters in the Bud. Evid Based Complement Alternat Med. 2011: 586506

17. Saini A. Physicians of ancient India. J Family Med Prim Care. 2016; 5: 254 258

18. Asl MN \& Hosseinzadeh H. Review of pharmacological effects of Glycyrrhiza sp. and its bioactive compounds. Phytother Res. 2008; 22: 709-724.

19. Yang R, Yuan BC, Ma YS, Zhou S \& Liu Y. The anti-inflammatory activity of licorice, a widely used Chinese herb. Pharm Biol. 2017; 55: 5-18.

20. Yu X, Bao Y, Meng X, Wang S, Li T, Chang X, et al. Multi-pathway integrated adjustment mechanism of licorice flavonoids presenting anti-inflammatory activity. Oncol Lett. 2019; 18: 4956-4963.

21. Gao $Y$, Lv X, Yang $H$, Peng $L$ \& Ci X. Isoliquiritigenin exerts antioxidative and anti-inflammatory effects via activating the KEAP-1/Nrf2 pathway and inhibiting the NF-kappaB and NLRP3 pathways in carrageenan-induced pleurisy. Food Funct. 2020; 11: 2522-2534

22. Kim SH, Hong JH, Yang WK, Geum JH, Kim HR, Choi SY, et al. Herbal Combinational Medication of Glycyrrhiza glabra, Agastache rugosa Containing Glycyrrhizic Acid, Tilianin Inhibits Neutrophilic Lung Inflammation by Affecting CXCL2, Interleukin-17/STAT3 Signal Pathways in a Murine Model of COPD. Nutrients. 2020: 12

23. Das D, Agarwal SK \& Chandola HM. Protective effect of Yashtimadhu (Glycyrrhiza glabra) against side effects of radiation/chemotherapy in head and neck malignancies. Ayu. 2011; 32: 196-199.

24. Cinatl J, Morgenstern B, Bauer G, Chandra P, Rabenau H \& Doerr HW Glycyrrhizin, an active component of liquorice roots, and replication of SARSassociated coronavirus. Lancet. 2003; 361: 2045-2046.

25. Hoever G, Baltina L, Michaelis M, Kondratenko R, Tolstikov GA, Doerr HW, et al. Antiviral activity of glycyrrhizic acid derivatives against SARS-coronavirus. J Med Chem. 2005; 48: 1256-1259.

26. Sharma V, Katiyar A \& Agrawal RC. Glycyrrhiza glabra: Chemistry and Pharmacological Activity. Sweeteners: Pharmacology, Biotechnology, and Applications. 2017; 87-100

27. Pastorino G, Cornara L, Soares S, Rodrigues F \& Oliveira M. Liquorice (Glycyrrhiza glabra): A phytochemical and pharmacological review. Phytother Res. 2018; 32: 2323-2339.

28. Pettersen EF, Goddard TD, Huang CC, Couch GS, Greenblatt DM, Meng EC, et al. UCSF Chimera--a visualization system for exploratory research and analysis. J Comput Chem. 2004; 25: 1605-1612.

29. Trott O \& Olson AJ. AutoDock Vina: improving the speed and accuracy of docking with a new scoring function, efficient optimization, and multithreading. Journal of computational chemistry. 2010; 31: 455-461

30. Dallakyan S \& Olson AJ. Small-molecule library screening by docking with PyRx. Methods Mol Biol. 2015; 1263: 243-250.

31. Abraham MJ, Murtola T, Schulz R, Páll S, Smith JC, Hess B, et al. GROMACS High performance molecular simulations through multi-level parallelism from laptops to supercomputers. Software X. 2015; 1-2: 19-25.

32. van Aalten DMF, Bywater R, Findlay JBC, Hendlich M, Hooft RWW \& Vriend G. PRODRG, a program for generating molecular topologies and unique molecular descriptors from coordinates of small molecules. Journal of Computer-Aided Molecular Design. 2006; 10: 255-262.

33. Kumari R, Kumar R \& Lynn A. g_mmpbsa-A GROMACS Tool for HighThroughput MM-PBSA Calculations. Journal of Chemical Information and Modeling. 2014; 54: 1951-1962.

34. Qureshi A, Kaur G \& Kumar M. AVCpred: an integrated web server for prediction and design of antiviral compounds. Chemical Biology \& Drug Design. 2017; 89: 74-83.

35. Pires DEV, Blundell TL \& Ascher DB. pkCSM: Predicting Small-Molecule Pharmacokinetic and Toxicity Properties Using Graph-Based Signatures. Journal of Medicinal Chemistry. 2015; 58: 4066-4072.

36. Lagunin A, Ivanov S, Rudik A, Filimonov D \& Poroikov V. DIGEP-Pred: web service for in silico prediction of drug-induced gene expression profiles based on structural formula. Bioinformatics. 2013; 29: 2062-2063.

37. Doncheva NT, Morris JH, Gorodkin J \& Jensen LJ. Cytoscape StringApp: Network Analysis and Visualization of Proteomics Data. J Proteome Res. 2019; 18: 623-632.

38. Pinn G. Herbal therapy in respiratory disease. Aust Fam Physician. 2001; 30: $775-779$

39. Santana FP, Pinheiro NM, Mernak MI, Righetti RF, Martins MA, Lago JH, et al. Evidences of Herbal Medicine-Derived Natural Products Effects in Inflammatory Lung Diseases. Mediators Inflamm. 2016: 2348968.

40. Alamgeer, Younis W, Asif H, Sharif A, Riaz H, Bukhari I, et al. Traditional medicinal plants used for respiratory disorders in Pakistan: a review of the ethno-medicinal and pharmacological evidence. Chin Med. 2018: 13.

41. Weiss RF \& Fintelmann V. Herbal medicine. Stuttgart; New York: Thieme. 
2000.

42. Vasanthi HR \& Parameswari RP. Indian spices for healthy heart - an overview. Curr Cardiol. 2010; 6: 274-279.

43. Sachan A, Kumar S, Kumari K \& Singh D. Medicinal uses of spices used in our traditional culture: World wide. Journal of Medicinal Plants Studies. 2018; 6: 116-122.

44. Maurya DK \& Sharma D. Evaluation of traditional ayurvedic Kadha for prevention and management of the novel Coronavirus (SARS-CoV-2) using in silico approach. J Biomol Struct Dyn. 2020; 1-16

45. El-Saber Batiha G, Magdy Beshbishy A, El-Mleeh A, Abdel-Daim MM \& Prasad Devkota H. Traditional Uses, Bioactive Chemical Constituents, and Pharmacological and Toxicological Activities of Glycyrrhiza glabra L. (Fabaceae). Biomolecules. 2020: 10.

46. Sabouri Ghannad M, Mohammadi A, Safiallahy S, Faradmal J, Azizi M \& Ahmadvand Z. The Effect of Aqueous Extract of Glycyrrhiza glabra on Herpes Simplex Virus 1. Jundishapur J Microbiol. 2014; 7: e11616.

47. Fukuchi K, Okudaira N, Adachi K, Odai-Ide R, Watanabe S, Ohno H, et al. Antiviral and Antitumor Activity of Licorice Root Extracts. In Vivo. 2016; 30: 777-785.

48. Ashraf A, Ashraf MM, Rafiqe A, Aslam B, Galani S, Zafar S, et al. In vivo antiviral potential of Glycyrrhiza glabra extract against Newcastle disease virus. Pak J Pharm Sci. 2017; 30: 567-572.

49. Pu JY, He L, Wu SY, Zhang P \& Huang X. Anti-virus research of triterpenoids in licorice. Bing Du Xue Bao. 2013; 29: 673-679.

50. Lindner HA, Fotouhi-Ardakani N, Lytvyn V, Lachance P, Sulea T \& Menard $\mathrm{R}$. The papain-like protease from the severe acute respiratory syndrome coronavirus is a deubiquitinating enzyme. J Virol. 2005; 79: 15199-15208.

51. Jo S, Kim S, Shin DH \& Kim MS. Inhibition of SARS-CoV 3CL protease by flavonoids. J Enzyme Inhib Med Chem. 2020; 35: 145-151.

52. Li F. Structure, Function, and Evolution of Coronavirus Spike Proteins. Annu Rev Virol. 2016; 3: 237-261.

53. Wang $Q$, Zhang $Y$, Wu L, Niu S, Song C, Zhang Z, et al. Structural and Functional Basis of SARS-CoV-2 Entry by Using Human ACE2. Cell. 2020.

54. Yuan Y, Cao D, Zhang Y, Ma J, Qi J, Wang Q, et al. Cryo-EM structures of MERS-CoV and SARS-CoV spike glycoproteins reveal the dynamic receptor binding domains. Nat Commun. 2017; 8: 15092.

55. Harris AJ, Thompson AR, Whyte MK \& Walmsley SR. HIF-mediated innate immune responses: cell signaling and therapeutic implications. Hypoxia (Auckl). 2014; 2: 47-58.

56. Birkenkamp KU \& Coffer PJ. FOXO transcription factors as regulators of immune homeostasis: molecules to die for? J Immunol. 2003; 171: 16231629.

57. Hammarén HM, Virtanen AT, Raivola J \& Silvennoinen O. The regulation of JAKs in cytokine signaling and its breakdown in disease. Cytokine. 2019 118: 48-63.

58. Huang C, Wang Y, Li X, Ren L, Zhao J, Hu Y, et al. Clinical features of patients infected with 2019 novel coronavirus in Wuhan, China. Lancet. 2020 395: 497-506.

59. Zhang W, Zhao Y, Zhang F, Wang Q, Li T, Liu Z, et al. The use of antiinflammatory drugs in the treatment of people with severe coronavirus disease 2019 (COVID-19): The Perspectives of clinical immunologists from China. Clin Immunol. 2020; 214: 108393

60. Mendes-Silva W, Assafim M, Ruta B, Monteiro RQ, Guimarães JA \& Zingali RB. Antithrombotic effect of Glycyrrhizin, a plant-derived thrombin inhibitor. Thromb Res. 2003; 112: 93-98. 